\title{
Bailouts and Financial Fragility
}

\author{
Todd Keister \\ Department of Economics \\ Rutgers University \\ todd.keister@rutgers.edu
}

January 25, 2014

\begin{abstract}
Should policy makers be prevented from bailing out investors in the event of a crisis? I study this question in a model of financial intermediation with limited commitment. When a crisis occurs, the policy maker will respond by using public resources to augment the private consumption of those investors facing losses. The anticipation of such a "bailout" distorts ex ante incentives, leading intermediaries to choose arrangements with excessive illiquidity and thereby increasing financial fragility. Prohibiting bailouts is not necessarily desirable, however: while it induces intermediaries to become more liquid, it may nevertheless lower welfare and leave the economy more susceptible to a crisis. A policy of taxing short-term liabilities, in contrast, can both improve the allocation of resources and promote financial stability.
\end{abstract}

I am grateful to participants at numerous conference and seminar presentations and especially to Giovanni Calice, Amil Dasgupta, Huberto Ennis, Antoine Martin, Alexander Monge-Naranjo, Robert Reed, Jaume Ventura and three anonymous referees for helpful comments. I also thank Vijay Narasiman and Parinitha Sastry for excellent research assistance. Parts of this work was completed while I was an economist at the Federal Reserve Bank of New York, a Fernand Braudel Fellow at the European University Institute, and a visiting scholar at the Stern School of Business, New York University; the hospitality and support of each of these institutions is gratefully acknowledged. 


\section{Introduction}

The recent financial crisis has generated a heated debate about the effects of public-sector bailouts of distressed financial institutions. Most observers agree that the anticipation of being bailed out in the event of a crisis distorts the incentives faced by these institutions and their investors. By insulating these agents from the full consequences of a negative outcome, an anticipated bailout leads to a misallocation of resources and encourages risky behavior that may leave the economy more susceptible to a crisis. Opinions differ widely, however, on the best way to deal with this problem.

Some observers argue that the focus should be on restricting future policy makers' ability to engage in bailouts. Such a restriction would encourage investors and intermediaries to provision for bad outcomes and, it is claimed, these actions would collectively make the financial system more stable. Swagel (2010), for example, argues "[a] resolution regime that provides certainty against bailouts will reduce the riskiness of markets and thus help avoid a future crisis." Similarly, Dijsselbloem (2013) states that "[b]y ensuring that the private sector bears the primary responsibility for bank resolution, market discipline will be increased and a sustainable, healthy financial sector can be achieved.” Rehm (2013) reports that one Federal Reserve bank president "wants to tie the government's hands so that regulators have no funds to finance these bailouts. Only then, [Lacker] argues, will market participants believe bailouts are over and begin to discipline financial companies themselves."

Credibly restricting the actions of future policy makers is difficult, of course, and it is not clear to what extent a strict no-bailouts policy is feasible. Nevertheless, many current reform efforts have embraced the view that such restrictions are desirable and should be pursued where possible. A leading example is the Dodd-Frank Wall Street Reform and Consumer Protection Act of 2010, which aims "to promote financial stability ... [and] to protect the American taxpayer by ending bailouts.” The Act prohibits several types of policy interventions that were used during the recent crisis by, for example, placing new restrictions on the ability of the Federal Reserve to lend funds and on the ability of the U.S. Treasury and the Federal Deposit Insurance Corporation to guarantee the debt of financial institutions. Moreover, the Act specifically states that "[t]axpayers shall bear no losses from the exercise of any authority under this title.” 
Is restricting policy makers's ability to bail out financial institutions an effective way to promote financial stability? Would doing so - if feasible - actually be desirable? I address these questions in a model of financial intermediation based on the classic paper of Diamond and Dybvig (1983). In particular, I study an environment with idiosyncratic liquidity risk and limited commitment, as in Ennis and Keister (2009a). Intermediaries perform maturity transformation, which leaves them illiquid and potentially susceptible to a self-fulfilling run by investors. I introduce fiscal policy by adding a public good whose production is financed through lump-sum taxes. This approach yields a tractable model in which bailouts affect the incentives of intermediaries and their investors and these agents' actions collectively determine the susceptibility of the financial system to a crisis.

I begin the analysis by studying equilibrium outcomes in this environment when there are no restrictions on the bailout policy. If a crisis occurs, the policy maker will respond by diverting some tax revenue away from the production of public goods, using these resources to instead support the private consumption of investors facing losses. These "bailout" payments aim to improve the allocation of the remaining resources in the economy, but have undesirable effects on ex ante incentives. In particular, bailouts reduce the incentive for intermediaries to privately provision for a crisis, which leads them to increase their short-term liabilities and become more illiquid. I characterize the conditions under which the financial system is fragile in the sense that a selffulfilling run can occur in equilibrium and show that as the incentive distortions associated with bailouts become more severe, the fragility of the financial system increases.

Adopting a no-bailouts policy in this environment would lead intermediaries to become more cautious and less illiquid, as emphasized by proponents of such policies. However, it would also increase the losses faced by investors who are late to withdraw in the event of a crisis. I show that a no-bailouts policy is unambiguously bad when the probability of a crisis is sufficiently small: it lowers equilibrium welfare without improving financial stability. For higher probabilities of a crisis, a no-bailouts policy may or may not be preferable, depending on parameter values. Interestingly, some economies that are not fragile when bailouts are allowed become susceptible to a self-fulfilling run if a no-bailouts policy is adopted.

The idea that a no-bailouts policy can make the financial system more fragile runs counter to conventional wisdom, but the mechanism behind this result is easy to see. Bailouts provide insurance: they reduce the loss an investor faces if she does do not withdraw her funds and a crisis occurs. Removing this insurance raises each individual's incentive to withdraw early if she expects 
others to do so, which makes the financial system more susceptible to a run. This argument is familiar in the context of retail banking, where government-sponsored deposit insurance programs are explicitly designed to promote stability by limiting depositors' incentive to withdraw. Despite this similarity, discussion of this insurance role of bailouts and its effect on investor withdrawal behavior has been largely absent in both the existing literature and the current policy debate.

A good policy arrangement in the environment studied here would permit bailouts to occur, so that investors benefit from the efficient level of insurance, while offsetting the negative effects on ex ante incentives. To demonstrate this fact, I allow the policy maker to levy a Pigouvian tax on intermediaries' short-term liabilities. I show that, in addition to improving the allocation of resources, this policy has a macroprudential component: it decreases financial fragility relative to either of the previous policy regimes. The results here thus argue for a shift in the focus of regulatory reform away from attempts to make future policy makers behave "tough" in times of crisis and toward developing more effective policy tools for correcting distorted incentives.

There is a growing literature on the incentive effects of financial-sector bailouts and optimal regulatory policy in the presence of limited commitment. In many of the settings that have been studied, bailouts serve no useful purpose from an ex ante point of view. Chari and Kehoe (2010), for example, study an environment in which committing to a no-bailouts policy would generate the constrained-efficient allocation of resources. When such commitment is infeasible, they show how renegotiation of contracts (i.e., “a bailout”) tends to undermine ex ante incentives and how regulation of private contracts can be welfare improving. In a similar vein, Farhi and Tirole (2012) study a setting in which the policy maker would like to commit to not lower interest rates in the event of a crisis. In the absence of commitment, the anticipation of this type of bailout distorts banks’ incentives and introduces a role for regulation. ${ }^{1}$

In the environment studied here, in contrast, a no-bailouts policy is never fully optimal. In this respect, the results are similar in spirit to those of Gale and Vives (2002), who study dollarization as a way for a central bank to commit to a no-bailouts policy. In their model, a central bank without commitment will engage in bailouts too often, undermining bank managers' incentives to exert effort. Dollarization - adopting another country’s currency - improves incentives by limiting bailouts, but causes projects to be liquidated in too many states. The desirability of restricting

1 Other related work includes Niepmann and Schmidt-Eisenlohr (2013), who examine the strategic interaction between governments when bailouts have international spillover effects, Ranciere and Tornell (2011), who show how the anticipation of a bailout can lead to welfare-reducing financial innovation, and Nosal and Ordoñez (2013), who study how uncertainty about the government's information set can mitigate the moral hazard associated with bailouts. 
bailouts thus depends on which of two competing effects dominates, much as in the environment I study here. Whereas the social benefit of bailouts in their model comes from avoiding costly liquidation, however, the benefit here comes from partially insuring investors against the risks associated with a crisis. ${ }^{2}$ This insurance not only promotes efficiency by encouraging intermediaries to undertake socially-valuable maturity transformation, but also promotes financial stability by making investors more willing to remain invested.

The next section presents the model. Section 3 analyzes the behavior of agents in the model (investors, intermediaries, and the policy maker) and studies equilibrium outcomes when bailouts are allowed. Section 4 provides the corresponding analysis under a no-bailouts policy. Section 5 shows how combining bailouts with a tax on short-term liabilities improves outcomes relative to either of these regimes and, finally, Section 6 offers some concluding remarks.

\section{The Model}

The analysis is based on a version of the Diamond and Dybvig (1983) model augmented to include limited commitment and a public good. This section describes the basic elements of the model and defines financial fragility in this setting.

\subsection{The environment}

There are three time periods, $t=0,1,2$, and a continuum of investors, indexed by $i \in[0,1]$. Each investor has preferences given by

$$
U\left(c_{1}, c_{2}, g ; \omega_{i}\right)=u\left(c_{1}+\omega_{i} c_{2}\right)+v(g)
$$

where $c_{t}$ is consumption of the private good in period $t$ and $g$ is the level of public good, which is provided in period 1 . The functions $u$ and $v$ are assumed to be strictly increasing, strictly concave, and to satisfy the usual Inada conditions. In addition, the coefficient of relative risk aversion for the function $u$ is assumed to be constant and greater than one. The parameter $\omega_{i}$ is a binomial random variable with support $\Omega_{i} \equiv\{0,1\}$ whose value is realized in period 1 and is private information. If $\omega_{i}=0$, investor $i$ is said to be impatient; if $\omega_{i}=1$, she is patient. Let $\pi$ denote the probability with which each individual investor will be impatient. By a law of large numbers, $\pi$ is also the fraction of investors in the population who will be impatient.

2 The idea that bailouts can be part of a desirable social insurance arrangement also appears, in different forms, in Green (2010) and Bianchi (2012). 
Each investor is endowed with one unit of the private good in period 0 . There is a single, constant-returns-to-scale technology for transforming this endowment into private consumption in the later periods. A unit of the good invested in period 0 yields $R>1$ units in period 2, but only one unit in period 1. This investment technology is operated in a central location, where investors can pool resources in an intermediation technology to insure individual liquidity risk. Investors are isolated from each other in periods 1 and 2 and no trade can occur among them. Upon learning her preference type, each investor chooses either to contact the intermediation technology in period 1 and withdraw funds or to wait and withdraw in period 2. There is also a technology for transforming units of the private good one-for-one into units of the public good. This technology is operated in period 1 , using goods that were placed into the investment technology in period 0.

Investors who choose to withdraw in period 1 arrive one at a time to the central location and must consume immediately upon arrival. As in Wallace (1988, 1990), this sequential-service constraint implies that the payment made to an investor can depend only on the information received by the intermediation technology up to that point, including the number of withdrawals that have taken place so far and possibly the aggregate state of the economy. Withdrawing investors arrive at the central location in the order given by their index $i$. In other words, investor $i=0$ knows that she has the opportunity to be the first investor to withdraw in period 1 , and investor $i=1$ knows his withdrawal opportunity in period 1 will be the last. An investor's position in the order is private information and her action is only observable when she chooses to withdraw. ${ }^{3}$

Welfare is measured by the equal-weighted average of investors’ expected utilities,

$$
W=\int_{0}^{1} E\left[U\left(c_{1}(i), c_{2}(i), g ; \omega_{i}\right)\right] d i .
$$

We can think of investors as being assigned their index $i$ randomly at the beginning of period 0 , in which case this expression measures the expected utility of each investor ex ante, before any individual-specific characteristics are revealed.

3 In Diamond and Dybvig (1983), investors first decide when to withdraw and then are randomly assigned positions in the withdrawal order. It seems natural, however, to suppose investors have some information about their position in this order before they must decide; an investor may realize, for example, that she is relatively late to act and that many withdrawals have already been made. Green and Lin (2003) showed how an investor's optimal choice can depend crucially on this information. Allowing investors to know their precise position in the order - as in Green and Lin (2000), Andolfatto et al.(2007) and Ennis and Keister (2009b) - is a tractible way of including these effects in the analysis. The precise approach here follows Ennis and Keister (2010), which studies the dyamics of withdrawls and policy responses. 


\subsection{The decentralized economy}

The intermediation technology is operated by a large number of identical intermediaries. Each correctly anticipates that a fraction $\pi$ of its investors will be impatient and behaves competitively in the sense that it considers its own effect on economy-wide resource constraints to be negligible. Intermediaries act to maximize the expected utility of their investors at all times. ${ }^{4}$ However, as in Ennis and Keister (2009a, 2010), they cannot commit to future actions. This inability to commit implies that they are unable to use the type of suspension-of-convertibility plans discussed in Diamond and Dybvig (1983) or the type of run-proof contracts studied in Cooper and Ross (1998) to eliminate undesirable equilibria. Instead, the payment given to each investor is always determined as a best response to the current situation when she withdraws.

The public good is provided by a benevolent policy maker who taxes deposits in period 0 at rate $\tau$ and places this revenue into the investment technology. In period 1 , the policy maker can use these resources to produce the public good and, if a crisis is underway, to make transfer ("bailout") payments to financial intermediaries. ${ }^{5}$ The policy maker is also unable to commit to future actions and cannot, for example, eliminate undesirable equilibria by promising to fully insure investors' deposits. Any bailout payments will be chosen as a best response to the situation at hand.

\subsection{Financial crises}

In order to allow a crisis to occur with nontrivial probability, I introduce an extrinsic signal on which investors can potentially condition their actions. Let $S=\{\alpha, \beta\}$ be the set of possible states and $\{1-q, q\}$ the probabilities of these states, respectively. Investor $i$ chooses a strategy that assigns an action to each possible realization of her preference type $\omega_{i}$ and of the state,

$$
y_{i}: \Omega_{i} \times S \rightarrow\{0,1\}
$$

where $y_{i}=0$ corresponds to withdrawing early and $y_{i}=1$ corresponds to waiting until period 2 . Let $y$ denote a profile of strategies for all investors. The state $s$ can be thought of as representing

$\overline{4}$ In reality, there are important agency problems that cause the incentives of financial intermediaries to differ from those of their investors and creditors. I abstract from these agency problems here and focus directly on the distortions in investors' incentives that are created by the anticipation of a bailout.

5 Notice that this type of bailout policy is entirely consistent with the sequential service constraint, since all taxes are collected before any consumption takes place. I assume the sequential service constraint applies to the policymaker as well as to the intermediaries and, hence, the approach here is not subject to the Wallace (1988) critique of Diamond and Dybvig (1983). Other papers have introduced taxation into the Diamond-Dybvig framework in a similar way; see, for example, Freeman (1988), Boyd et al. (2002), and Martin (2006). The goal of fiscal policy in those papers, however, is to fund a deposit insurance system rather than to pursue an independent objective like the provision of a public good. 
investor sentiment; it has no fundamental impact on the economy, but in equilibrium it may be informative about the withdrawal plans of other investors.

Under all of the policy regimes considered here, the model has an equilibrium with $y_{i}\left(\omega_{i}, s\right)=$ $\omega_{i}$ for all $i$ in both states. In other words, there is always a "good" equilibrium in which investors withdraw in period 1 only if they are impatient. Since no crisis occurs in this equilibrium, no bailout payments are made and no incentive distortions arise. As a result, this equilibrium implements the first-best allocation of resources. The question of interest is whether there exist other, "bad" equilibria in which some patient investors run by withdrawing early in some state. Without loss of generality, I focus on strategy profiles in which a run occurs in state $\beta$.

Definition 1: The financial system is fragile if there exists an equilibrium strategy profile with $y_{i}(1, \beta)=0$ for a positive measure of investors.

Fragility thus captures the idea that the financial system is susceptible to a run based on shifting investor sentiment.

\subsection{Timeline}

The timing of decisions is summarized in Figure 1. In period 0, investors deposit their endowments with intermediaries and immediately exit the central location. The policy maker then collects a fraction $\tau$ of total deposits as tax revenue. Intermediaries make no decisions in this stage, since there is a single asset (and thus no portfolio choice) and they cannot commit to any future payment scheme.

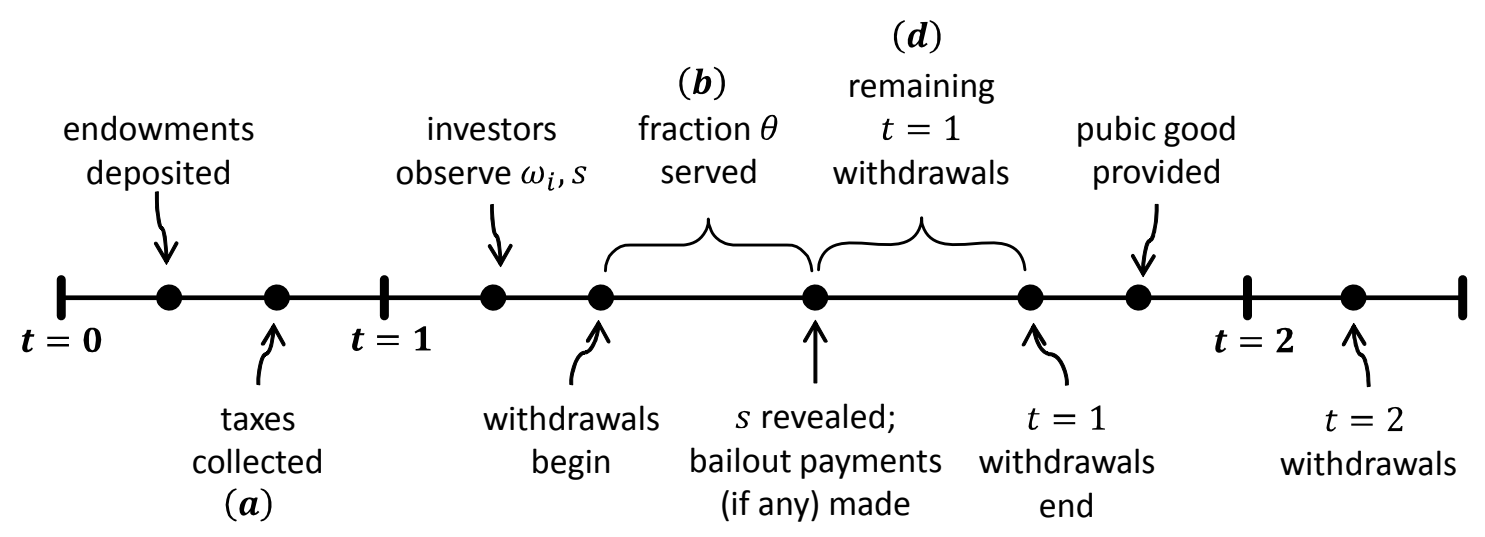

(c)

Figure 1: Timeline 
At the beginning of period 1, investors are isolated from each other and from the intermediaries. After observing her own preference type $\omega_{i}$ and the state $s$, each investor chooses whether to withdraw in period 1 or wait. Those investors who chose to withdraw in period 1 then begin to arrive at their intermediaries one at a time, in the order determined by the index $i$. The amount of consumption a withdrawing investor receives is determined by her intermediary as a best response to the current situation when she arrives. In particular, note that this payment is determined after investors have made their withdrawal decisions and thus cannot be used as a tool to influence withdrawal behavior. A withdrawing investor consumes as soon as she receives the payment from her intermediary and returns to isolation.

While investors observe the realization of $s$ at the beginning of period 0 , intermediaries and the policy maker observe the state with a lag, after a fraction $\theta \in(0, \pi]$ of investors have withdrawn. If the state is $\beta$ and a crisis is underway, the policy maker can choose to bail out intermediaries by transferring some tax revenue to each of them. Intermediaries combine this transfer with their own remaining funds and continue to serve withdrawing investors, making payments that are based on their updated information. The parameter $\theta$ thus measures the speed with which both intermediaries and the policy maker are able to react to an incipient crisis.

By the end of period 1, all investors who chose to withdraw early have been served and the policy maker uses its remaining funds to provide the public good. In period 2, those investors who have not yet withdrawn contact their intermediary. Since all uncertainty has been resolved at this point, an intermediary will choose to divide its remaining resources evenly among these investors.

\subsection{Discussion}

The model follows Green and Lin (2003), Peck and Shell (2003) and others in allowing intermediaries to offer any payment schedule that is consistent with the information structure of the environment. Under this approach, a fully-anticipated financial crisis cannot occur. If intermediaries expected all investors to withdraw early in both states, for example, their best response would be to simply give each investor the after-tax value of her initial deposit back when she withdraws. When an intermediary follows this policy, however, an individual patient investor has no incentive to join the run; she would prefer that the intermediary keep her funds until period 2 and earn the return $R>1$. In order for a crisis to arise in this setting, therefore, it must be the case that intermediaries and the policy maker are initially uncertain about investors' actions. Moreover, they must remain uncertain about these actions while some withdrawals are being made. If intermediaries 
were able to observe the state before any withdrawals take place - that is, if $\theta$ were zero - the above logic would apply once the state is revealed. When $\theta$ is positive, however, intermediaries must make payments to some investors before observing the state. In this case, once an intermediary discovers a run is underway, it may not longer be feasible to give each remaining investor the after-tax value of her initial deposit back in period 1. A patient investor may then prefer to join the run, depending on her position in the withdrawal order.

Previous work has assumed that intermediaries and policy makers never observe the state, but instead must infer the state from the flow of withdrawals. In the equilibria I study below, they would be able to infer that a run is underway if the fraction of investors withdrawing goes above $\pi$, the fraction of impatient investors. In the special case of $\theta=\pi$, therefore, the approach I introduce here is equivalent to that in the existing literature. For $\theta<\pi$, this more general approach allows one to study how equilibrium outcomes depend on the speed of the policy reaction to an incipient crisis. I show, for example, how the minimal value of $\theta$ necessary to generate financial fragility varies across policy regimes.

Some of the existing literature avoids the issue of how quickly intermediaries and policy makers can identify a run by assuming that investors must be given a pre-specified payout until an intermediary is completely out of funds. Under this "simple contracts" approach, intermediaries and policy makers are assumed to be unable to react to any information they receive and, hence, the issue of when they can observe or infer the state is irrelevant. ${ }^{6}$ While this approach is often analytically convenient, it is at odds with the fact that the liabilities of financial intermediaries are routinely altered during periods of crisis. In the Argentinean crisis of 2001-2, for example, bank deposits were partially frozen, dollar-denominated deposits were forcibly converted to pesos at an unfavorable exchange rate, and some deposits were replaced with long-term bonds. ${ }^{7}$ Similarly, in the Cypriot banking crisis of March 2013, all deposits were partially frozen and some deposits were forcibly converted to equity as part of the bailout package funded by the European Stability Mechanism and the International Monetary Fund. The approach here captures the salient features of these episodes and highlights the importance of the anticipated timing and form of the policy reaction to a crisis in determining the fragility of the financial system.

\footnotetext{
$6 \quad$ See, for example, Postlewaite and Vives (1987), Cooper and Ross (1998), and Allen and Gale (2004), among many others. Gale and Vives (2002) assume that banking contracts are fixed in nominal terms, but allow the central bank to "bail out" banks by raising the price level, which lowers the real value of their liabilities. In the environment here, in contrast, intermediaries can directly make payments to investors contingent on the state once it is observed and bailouts instead consist of fiscal transfers from the public sector to private investors.

7 See Dominguez and Tesar (2007) and Ennis and Keister (2009a) for a more informtion about these events.
} 


\section{Equilibrium with Bailouts}

I begin the analysis by studying equilibrium when there are no restrictions on the policy maker's choice of bailout payments. I ask under what conditions the financial system is fragile in this regime and derive the equilibrium allocation of resources in these cases. To do so, I first study a particular strategy profile in which some patient investors withdraw early in state $\beta$ but others do not. I then show that the financial system is fragile if and only if there is an equilibrium in which investors follow this particular profile.

\subsection{A partial-run strategy profile}

Consider the following strategy profile for investors:

$$
\begin{array}{ll}
y_{i}\left(\omega_{i}, \alpha\right)=\omega_{i} & \text { for all } i \text { and } \\
y_{i}\left(\omega_{i}, \beta\right)=\left\{\begin{array}{c}
0 \\
\omega_{i}
\end{array}\right\} & \text { for }\left\{\begin{array}{l}
i \leq \theta \\
i>\theta
\end{array}\right\} .
\end{array}
$$

Under this profile, impatient investors withdraw in period 1 in both states, as must occur in any equilibrium since they only value consumption in period 1. All patient investors wait until period

2 in state $\alpha$, but in state $\beta$ those patient investors who have an opportunity to withdraw relatively early in period 1 - before intermediaries and the policy maker observe the state - choose to do so. The profile thus represents a partial run on the financial system in state $\beta$.

In the subsections that follow, I derive the best responses of intermediaries and the policy maker to this strategy profile by working backward through the decisions labelled with letters in Figure 1, establishing: $(d)$ how intermediaries allocate their remaining resources after the state is revealed and any bailouts payments have been made, $(c)$ what bailout payments the policy maker would choose to make in the event of a crisis, (b) how the anticipation of these bailout payments affects intermediaries' incentives as the first fraction $\theta$ of investors withdraw, and $(a)$ what tax rate the policy maker will choose in period 0. I then show how these best responses determine investors' withdrawal incentives and the fragility of the financial system.

\subsection{The allocation of remaining private consumption}

First, consider decision $(d)$ for intermediary $j$, which arises after a fraction $\theta$ of the intermediary's investors have withdrawn, the state has been revealed, and any bailout payments have been made. Let $\psi_{s}^{j}$ denote the quantity of resources the intermediary has available for its remaining investors. 
From the strategy profile (1) and the observed state $s$, the intermediary can calculate the fraction $\widehat{\pi}_{s}$ of these investors who are impatient and will withdraw in period 1 , which is either

$$
\widehat{\pi}_{\alpha} \equiv \frac{\pi-\theta}{1-\theta} \quad \text { or } \quad \widehat{\pi}_{\beta} \equiv \pi
$$

Since all uncertainty has been resolved at this point, the intermediary will choose to give a common amount $c_{1 s}^{j}$ to each remaining impatient investor in period 1 and a common amount $c_{2 s}^{j}$ to each remaining patient investor in period 2 . These payments will be chosen to solve

$$
V\left(\psi_{s}^{j} ; \widehat{\pi}_{s}\right) \equiv \max _{\left\{c_{1 s}^{j}, c_{2 s}^{j}\right\}}(1-\theta)\left[\widehat{\pi}_{s} u\left(c_{1 s}^{j}\right)+\left(1-\widehat{\pi}_{s}\right) u\left(c_{2 s}^{j}\right)\right]
$$

subject to the feasibility constraint

$$
(1-\theta)\left[\widehat{\pi}_{s} c_{1 s}^{j}+\left(1-\widehat{\pi}_{s}\right) \frac{c_{2 s}^{j}}{R}\right]=\psi_{s}^{j} .
$$

Letting $\mu_{s}^{j}$ denote the multiplier on the constraint, the solution to the problem is characterized by the first-order condition

$$
u^{\prime}\left(c_{1 s}^{j}\right)=R u^{\prime}\left(c_{2 s}^{j}\right)=\mu_{s}^{j} .
$$

It is straightforward to show that the optimal values of both $c_{1 s}^{j}$ and $c_{2 s}^{j}$ are strictly decreasing functions of $\widehat{\pi}_{s}$. When a larger fraction of the remaining investors are impatient, fewer resources are held in the investment technology long enough to earn the return $R$ and the intermediary responds by allocating less consumption to each of its remaining investors.

\subsection{Bailout policy}

Next, consider decision $(c)$ in Figure 1, which arises when the policy maker observes the state to be $\beta$. In this case, the policy maker knows that a run has occurred as specified in (1) and, therefore, that some of the $\theta$ investors who have already withdrawn were actually patient. As a result, a relatively large fraction of the remaining investors $-\widehat{\pi}_{\beta}$ from equation (2) - are impatient and need to consume in period 1 . These additional early withdrawals will lower the consumption levels $\left\{c_{1 s}^{j}, c_{2 s}^{j}\right\}$ of the remaining investors as described above. The policy maker can mitigate this decline by making bailout payments $\left\{b^{j}\right\}$ to intermediaries using the tax revenue collected in period 0 . In making these payments, the policy maker will aim to efficiently divide the economy's remaining resources between public and private consumption, recognizing that each intermediary 
will allocate whatever resources it has available according to (3). Let $\sigma(j)$ denote the distribution of investors across intermediaries, so that the total size of the bailout package is given by

$$
b \equiv \int b^{j} d \sigma(j) .
$$

The policy maker will choose the bailout payments to solve

$$
\max _{\left\{b^{j}\right\}} \int V\left(\psi_{\beta}^{j} ; \widehat{\pi}_{\beta}\right) d \sigma(j)+v(\tau-b)
$$

subject the resource constraints

$$
\psi_{\beta}^{j}=1-\tau-\theta c_{1}^{j}+b^{j} \quad \text { for all } j .
$$

These constraints state that the resources available to intermediary $j$, measured in per-investor terms, equal the initial deposit minus the tax $\tau$ and whatever payment $c_{1}^{j}$ was made to the fraction $\theta$ of investors who have already withdrawn, plus the bailout payment $b^{j}$.

The first-order condition for this problem requires

$$
v^{\prime}(\tau-b)=\mu_{\beta}^{j} \quad \text { for all } j
$$

which says that the policy maker will equate the marginal value of public consumption in state $\beta$ to the marginal value of private consumption in that state for the remaining investors in each intermediary. In other words, the solution to this problem must equalize the marginal value of resources $\mu_{\beta}^{j}$ across all intermediaries. For a given size of the total bailout package $b$ per investor, this entails setting

$$
b^{j}=b+\theta\left[c_{1}^{j}-\bar{c}_{1}\right] \quad \text { for all } j,
$$

where $\bar{c}_{1} \equiv \int c_{1}^{j} d \sigma(j)$ is the economy-wide average of the payment $c_{1}^{j}$ given to the fraction $\theta$ of investors who have already withdrawn. The remaining resources $\psi_{\beta}^{j}$ available to intermediary $j$ will then depend only on aggregate conditions,

$$
\psi_{\beta}^{j}=1-\tau-\theta \bar{c}_{1}+b
$$

which the intermediary takes as given, and not on its own choice of $c_{1}^{j}$.

The incentive problems created by this policy are clear: an intermediary with fewer remaining resources (because it set $c_{1}^{j}$ higher) will receive a larger bailout payment. This larger payment 
implies that fewer funds are available for making transfers to other intermediaries and for public consumption. In equilibrium, of course, all intermediaries will choose the same value of $c_{1}^{j}$ and receive the same bailout payment $b^{j}$ per investor, but these values will be higher than is socially desirable because of the external effect each intermediary's choice has in state $\beta{ }^{8}$

\subsection{Distorted incentives}

Moving to decision $(b)$ in Figure 1, intermediary $j$ must decide how much consumption to give to each of the fraction $\theta$ of investors who withdraw before it observes the state. Since no information is revealed as these withdrawals take place, the intermediary will choose to give the same amount $c_{1}^{j}$ to each of them. The value of $c_{1}^{j}$ will be chosen to maximize

$$
\theta u\left(c_{1}^{j}\right)+(1-q) V\left(1-\tau-\theta c_{1}^{j} ; \widehat{\pi}_{\alpha}\right)+q V\left(1-\tau-\theta \bar{c}_{1}+b ; \widehat{\pi}_{\beta}\right)
$$

The first term corresponds to the fraction $\theta$ of the intermediary's investors who will receive the chosen amount $c_{1}^{j}$. The second and third terms represent the expected utility from distributing the intermediary's remaining resources in each state - including the bailout payment $b^{j}$ in state $\beta$ according to the efficient plan from (3).

The first-order condition for this problem is

$$
\begin{aligned}
u^{\prime}\left(c_{1}^{j}\right) & =(1-q) V^{\prime}\left(1-\tau-\theta c_{1}^{j} ; \widehat{\pi}_{\alpha}\right) \\
& =(1-q) \mu_{\alpha}^{j}
\end{aligned}
$$

This condition highlights the incentive distortion described above: the intermediary chooses $c_{1}^{j}$ to equate the marginal value of resources before the state is known to the expected shadow value of resources in the no-run state, ignoring the value of resources in the event of a run. This behavior is individually optimal because the bailout policy (7) implies that the resources available to the intermediary in the run state will be independent of its own choice of $c_{1}^{j}$.

Condition (10) implicitly defines the intermediary's optimal choice of $c_{1}^{j}$ as a function of the tax rate $\tau$. Since all intermediaries face the same decision problem, I omit the index $j$ and denote this function by $c_{1}(\tau)$. Note that $c_{1}(\tau)$ does not depend on the choices of other intermediaries, as

8 Note that, in principle, a similar incentive problem could arise in state $\alpha$ if the policymaker made bailout payments to intermediaries that chose an unusually high level of $c_{1}^{j}$ in that state as well. I assume that bailout payments are only made in the event of a financial crisis. This assumption could be justified by reputation concerns, which will be significant for decisions made in normal times but much less important for a policymaker facing a rare event like a financial crisis. 
summarized by $\bar{c}_{1}$, nor on the size of the bailout package $b$. While these variables are important determinants of investors' consumption in state $\beta$, condition (10) shows that they do not affect an intermediary's optimal choice at decision $(b)$ in the figure.

Using (5) and (10), we see that the solution to this problem will satisfy $c_{1}<c_{2 \alpha}$ as long as

$$
q<\frac{R-1}{R}
$$

If this inequality were reversed, a patient investor would prefer to withdraw early even if all other patient investors choose to wait. In such cases, the profile in (1) is not consistent with equilibrium, but other, more complex partial-run strategy profiles may be. To avoid these complications, I restrict attention to the case (11), where the probability of a crisis is sufficiently small, throughout the analysis.

\subsection{Choosing the tax rate}

In decision $(a)$, the policy maker will choose the tax rate $\tau$ to maximize ex ante welfare,

$$
\theta u\left(c_{1}(\tau)\right)+(1-q)\left[V\left(\psi_{\alpha} ; \widehat{\pi}_{\alpha}\right)+v\left(g_{\alpha}\right)\right]+q\left[V\left(\psi_{\beta} ; \widehat{\pi}_{\beta}\right)+v\left(g_{\beta}\right)\right]
$$

subject to the resource constraints

$$
\begin{aligned}
& \psi_{\alpha}=1-\tau-\theta c_{1}(\tau) \quad \text { and } \\
& \psi_{\beta}=1-\tau-\theta c_{1}(\tau)+b(\tau),
\end{aligned}
$$

and the government budget constraint in each state,

$$
g_{\alpha}=\tau \quad \text { and } \quad g_{\beta}=\tau-b(\tau)
$$

where the function $c_{1}(\tau)$ is implicitly defined by (10) and the function $b(\tau)$ by (6). The first-order condition for this problem is

$$
\begin{aligned}
\left(u^{\prime}\left(c_{1}(\tau)\right)-(1-q) \mu_{\alpha}-q \mu_{\beta}\right) \theta \frac{d c_{1}}{d \tau}= & (1-q)\left[\mu_{\alpha}-v^{\prime}(\tau)\right] \\
& +q\left[\mu_{\beta}-v^{\prime}(\tau-b)\right]\left(1-\frac{d b}{d \tau}\right) .
\end{aligned}
$$

Note that (6) implies that the term in square brackets on the second line of this equation is zero. Because the size of the bailout package will be chosen to equate the marginal values of public and 
private consumption in state $\beta$, the first-order effect of changes in $b$ on welfare is zero. Using this fact and (10), the first-order condition simplifies to

$$
v^{\prime}(\tau)=\mu_{\alpha}+\frac{q}{1-q} \mu_{\beta} \theta \frac{d c_{1}}{d \tau}
$$

If the probability of a crisis $q$ were zero, the tax rate would be set to equate the marginal value of the public good in state $\alpha$ with the corresponding marginal value of private consumption, which is the standard Samuelson condition for the efficient provision of a public good. When $q$ is positive, the policy maker recognizes that $\tau$ affects intermediaries' choice of $c_{1}$ and, hence, can be used to partially correct the incentive distortion caused by the bailout policy. It is straightforward to show from (10) that $d c_{1} / d \tau$ is negative, which implies that increases in either the probability of the crisis state or the value of resources in that state will lead the policy maker to set the tax rate higher.

\subsection{Equilibrium and Fragility}

The above analysis establishes that the best responses of intermediaries and the policy maker to the strategy profile (1) under the policy regime with bailouts can be summarized by a vector

$$
\mathbf{c}^{B} \equiv\left\{c_{1}^{B},\left\{c_{1 s}^{B}, c_{2 s}^{B}, g_{s}^{B}\right\}_{s=\alpha, \beta}\right\}
$$

that specifies the private consumption levels of each investor and the level of public consumption in each state. The components of this vector are jointly determined by equations (4) - (6), (10), (13) - (15), and (17).

When does the economy have an equilibrium in which investors follow the partial-run strategy profile (1)? To answer this question, we must examine the incentives generated by the allocation vector $\mathbf{c}^{B}$ for each investor, comparing the level of consumption she would receive if she withdraws early to that she would receive if she waits. An impatient investor will always strictly prefer to withdraw early, as specified in the profile, so we only need to consider the actions of patient investors. Condition (5) implies that $c_{1 s}^{B}<c_{2 s}^{B}$ holds for any value of $\widehat{\pi}_{s}$ and, hence, a patient investor with $i>\theta$ will prefer to wait until period 2 to withdraw in both states. ${ }^{9}$ As mentioned above, condition (11) implies that $c_{1}^{B}<c_{2 \alpha}^{B}$ always holds, so that a patient investor with $i \leq \theta$

9 This result implies that a run in this model is necessarily partial. Once an intermediary observes the state, its reaction will be such that the remaining patient investors have no incentive to withdraw early. See Ennis and Keister (2010) for a related model in which an intermediary never observes the state, but is able to gradually make inferences about it from the flow of withdrawals. In that setting, a run must occur in waves, with only some investors withdrawing in each wave. 
will strictly prefer to wait in state $\alpha$. The only question, therefore, is whether a patient investor with $i \leq \theta$ has an incentive to join the run in state $\beta$. If she does, she will arrive before the state is revealed and will receive $c_{1}^{B}$. If she deviates by waiting until period 2 , she will receive $c_{2 \beta}^{B}$. We can, therefore, construct an equilibrium in which investors follow (1) if and only if the allocation $\mathbf{c}^{B}$ satisfies

$$
c_{1}^{B} \geq c_{2 \beta}^{B} .
$$

The following proposition shows that this condition is also necessary for fragility to arise; if the inequality is reversed, there is no equilibrium strategy profile in which some patient investors withdraw early in state $\beta$. Proofs of all results are given in the appendix unless otherwise noted.

Proposition 1 The financial system is fragile under the bailouts regime if and only if (18) holds.

In comparing outcomes across different policy regimes, it will be useful to study the set of all economies that are fragile under a given regime. An economy is characterized by the parameters $e \equiv(R, \pi, u, v, \theta, q)$. Let $\Phi^{B}$ denote the set of economies that are fragile in the bailouts regime. Proposition 1 establishes that $e \in \Phi^{B}$ if and only if (18) holds, in which case $\mathbf{c}^{B}$ represents the allocation of resources in the equilibrium where investors follow (1).

Figure 2 depicts the set $\Phi^{B}$ as the parameters $q$ and $\theta$ are varied using the utility functions

$$
u(c)=\frac{c^{1-\gamma}}{1-\gamma} \quad \text { and } \quad v(g)=\delta \frac{g^{1-\gamma}}{1-\gamma}
$$

with three different values of $\delta$. The other parameter values are given by $(R, \pi, \gamma)=(1.05,1 / 2,8)$. Two general patterns stand out in all three panels of the figure. First, for a given value of $q$, the delay parameter $\theta$ must be sufficiently large for the financial system to be fragile. When $\theta$ is small, intermediaries are able to react quickly to an incipient run by adjusting payments to a level that is appropriate given the high withdrawal demand. This quick reaction ensures that the losses created by the run are small and, as a result, the payoff to a patient investor from waiting to withdraw, $c_{2 \beta}$, remains higher than the payoff from joining the run, $c_{1}$. Second, the threshold value of $\theta$ decreases with $q$. As a crisis becomes more likely, intermediaries have an incentive to give a higher return to the first fraction $\theta$ of investors who withdraw because there are no consequences of having done so if the crisis state occurs, as shown in (8). This higher return makes withdrawing early more attractive to a patient investor, which makes the financial system fragile for lower values of $\theta$. As 


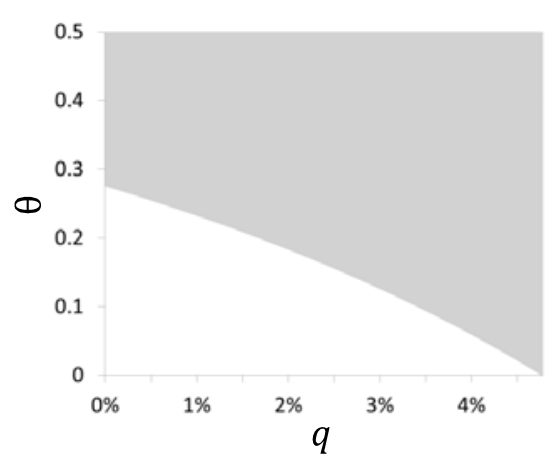

(a) $\delta=10^{-5}$

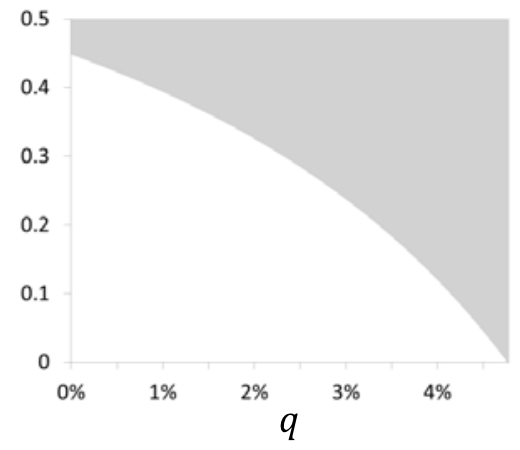

(b) $\delta=1$

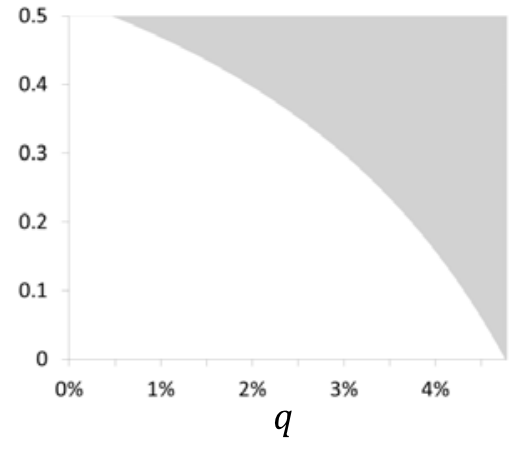

(c) $\delta=10$

Figure 2: The fragile set $\Phi^{B}$ under the bailouts regime

$q$ approaches the bound in (11), this threshold drops to zero: even if the the intermediary is able to react almost immediately to a run, the first few patient investors will still have an incentive to withdraw early.

The parameter $\delta$ in this example measures the relative importance of the public good and is a key determinant of the tax rate $\tau$. When $\delta$ is small, as in panel (a) of the figure, the policy maker collects relatively little tax revenue in period 0 and the bailout payments $b^{j}$ made in state $\beta$ are correspondingly small. As $\delta$ increases, the policy maker collects more tax revenue in order to provide more of the public good. If a crisis occurs, the bailout payments determined by equation (6) are then larger, which raises the private consumption levels $\left(c_{1 \beta}, c_{2 \beta}\right)$ and makes withdrawing early less attractive to a patient investor. For this reason, the set $\Phi^{B}$ shrinks as we move to panels (b) and (c). This effect is particularly pronounced for lower values of the probability $q$, where the incentive distortions associated with bailouts are small.

\subsection{Discussion}

It is worth noting that there is no role for liquidity facilities or other forms of lending to the financial sector in this model, even though a crisis is driven by self-fulfilling beliefs. Once intermediaries and the policy maker realize a run is underway, the problem is no longer one of illiquidity in the financial system because all future payments will be adjusted based on this information. Instead, the problem is that some patient investors have already withdrawn, creating a misallocation of resources that shrinks the set of feasible consumption levels $\left(c_{1 s}, c_{2 s}\right)$ for the remaining investors. The only way to mitigate the losses suffered by these investors is through real transfers from the public sector. 
The model also highlights a key conceptual difference between bailouts and deposit insurance programs. Deposit insurance is an ex ante commitment that aims to influence withdrawal behavior by assuring investors that they will not suffer losses. A bailout, in contrast, is an ex post response that aims to mitigate the effects of a crisis. The following proposition shows that the policy maker's best response to a crisis is never to provide full deposit insurance; investors who are late to withdraw always suffer losses in the crisis state.

Proposition 2 For any $e \in \Phi^{B}$, we have $\left(c_{1 \beta}^{*}, c_{2 \beta}^{*}, g_{\beta}^{*}\right) \ll\left(c_{1 \alpha}^{*}, c_{2 \alpha}^{*}, g_{\alpha}^{*}\right)$.

Fully insuring deposits would shift all of the losses associated with a crisis onto the public sector, raising the marginal value of public consumption in state $\beta$ above investors' marginal utility of private consumption. Instead, the best-response bailout policy in (6) divides the losses between the public and private sectors, which implies that investors' funds in the financial system are only partially insured. ${ }^{10}$

In the sections that follow, I analyze two policy measures that aim to mitigate the incentive problem associated with bailouts and improve welfare, beginning with a prohibition on bailouts.

\section{Equilibrium under a No-Bailouts Policy}

I now study equilibrium under a regime where the policy maker is required to set $b^{j}=0$ for all intermediaries in all states of nature. As described in the introduction, the idea that eliminating future bailouts is an effective way to discourage risky behavior and thereby promote financial stability has figured prominently in recent policy debates. In the environment studied here, a no-bailouts policy does indeed lead intermediaries to be more cautious. However, it is often undesirable and may actually increase financial fragility.

The analysis follows the same steps as in the previous section. In particular, I derive the best responses of intermediaries and the policy maker to the strategy profile in (1) by again working backward through the labelled decisions in Figure 1. Decision $(d)$ is unchanged: intermediaries

10 If the policy maker could commit in period 0 to fully insure investors' funds in subsequent periods, waiting to withdraw in period 2 would become a dominant strategy for all patient investors and a bank run would never occur in equilibrium, as in Diamond and Dybvig (1983, Section V). The policy maker may or may not need to collect extra taxes in period 0 for this commitment to be credible, depending on parameter values. Cooper and Kempf (2011) study a model with heterogeneous agents in which a policy maker without commitment makes a binary choice between providing full deposit insurance and taking no action. They show that whether deposit insurance will be provided ex post depends on how the policy redistributes wealth across agents. 
will still allocate their remaining resources according to (3). Decision $(c)$ is now trivial: the policy maker is required to set $b^{j}=0$ for all $j$. The analysis for this case begins, therefore, with decision (b), in which intermediaries choose how much consumption to give to each of the fraction $\theta$ of their investors who withdraw before the state is revealed.

\subsection{Corrected incentives, but ...}

Under a no-bailouts regime, each intermediary must use its own resources to provide consumption to all of its investors in both states. When faced with decision $(b)$ in Figure 1, intermediary $j$ will now choose $c_{1}^{j}$ to solve

$$
\max _{\left\{c_{1}^{j}\right\}} \theta u\left(c_{1}^{j}\right)+(1-q) V\left(1-\tau-\theta c_{1}^{j} ; \widehat{\pi}_{\alpha}\right)+q V\left(1-\tau-\theta c_{1}^{j} ; \widehat{\pi}_{\beta}\right) .
$$

Note the crucial difference between this expression and (9): the quantity of resources available to intermediary $j$ after $\theta$ withdrawals is now the same in both states and depends on the intermediary's choice of $c_{1}^{j} \cdot{ }^{11}$ The first-order condition for this problem is

$$
u^{\prime}\left(c_{1}\right)=(1-q) \mu_{\alpha}+q \mu_{\beta}
$$

Comparing (19) with (10) shows how the no-bailout policy changes incentives. An intermediary now equates the marginal value of resources before it observes the state to the expected future value of resources, taking into account both possible outcomes.

In decision $(a)$ in Figure 1, the policy maker will again choose the tax rate $\tau$ to maximize (12) subject to the resource constraints (13) and (14), but with the function $c_{1}(\tau)$ now defined by (19) and with $b(\tau)$ set to zero, which implies

$$
g_{\alpha}=g_{\beta}=\tau
$$

The first-order condition is again given by (16), but with both $b$ and the derivative $d b / d \tau$ set to zero. Note that (19) implies that the left-hand side of this equation is now zero. When intermediaries choose $c_{1}$ taking into account the marginal value of resources in both possible states, the first-order effect of changes in $c_{1}$ on welfare are zero. Using this fact, condition (16) simplifies to

$$
v^{\prime}(\tau)=(1-q) \mu_{\alpha}+q \mu_{\beta}
$$

\footnotetext{
$1 \overline{1}$ The allocation of these resources $\left(c_{1 s}, c_{2 s}\right)$ will be different in the two states, of course, because the fraction
} $\widehat{\pi}_{s}$ of the remaining investors who are impatient differs across states as shown in (2). 
Because all tax revenue must now go into the public good in both states, the policy maker sets the marginal value of public consumption equal to the expected marginal value of private consumption.

Let $\mathbf{c}^{N}$ denote the allocation vector characterized by equations (4), (5), (13), (14) with $b(\tau)=0$, and (19) - (21). This allocation represents the best responses of intermediaries and the policy maker to the strategy profile (1) under a no-bailouts policy. As in the previous section, the condition

for financial fragility can be expressed in terms of two elements in this vector, as shown by the following proposition.

Proposition 3 The financial system is fragile under the no-bailouts regime if and only if $c_{1}^{N} \geq c_{2 \beta}^{N}$ holds.

The proof, which follows that of Proposition 1 closely, is omitted. Let $\Phi^{N}$ denote the set of economies $e$ for which this condition holds.

\subsection{Competing effects on fragility}

Moving from the bailouts regime to a no-bailouts policy has two, competing effects on financial fragility. First, intermediaries become more cautious when dealing with the first $\theta$ investors to withdraw. To make this statement precise, define the degree of illiquidity in the financial system to be

$$
\rho \equiv \frac{\theta c_{1}}{1-\tau}
$$

Since a fraction $\theta$ of investors will withdraw $c_{1}$ before intermediaries or the policy maker are able to react to an incipient crisis, the numerator of this expression has a natural interpretation as the total short-term liabilities of the financial system. The denominator is the period- 1 value of intermediaries' total assets. In other words, $\rho$ is the ratio of the short-term liabilities of the financial system to the short-run value of its assets, a natural measure of illiquidity. The following proposition shows that a no-bailouts policy reduces illiquidity in the financial system.

Proposition $4 \quad \rho^{N}<\rho^{B}$ holds for all $q>0$.

This result captures the popular idea that, by eliminating the incentive distortions associated with bailouts, a no-bailouts policy will lead intermediaries to hold more resources in reserve as a provision against bad outcomes. These actions lower the return earned by investors who withdraw early and thus tend to reduce the incentive for patient investors to run. 
However, prohibiting bailouts has another effect on investors' withdrawal incentives. For a given value of $c_{1}$, a crisis now leads to lower consumption levels $\left(c_{1 \beta}, c_{2 \beta}\right)$ for the remaining $(1-\theta)$ investors because no public funds are available to mitigate their losses. These lower payoffs tend to increase the incentive for those patient investors with $i \leq \theta$ to withdraw early, while the payment $c_{1}$ is still available.

The net effect of a no-bailouts policy on financial fragility is thus ambiguous: while it leads intermediaries to become more cautious, it also makes some investors' payoffs more sensitive to the withdrawal behavior of others. The next proposition shows that either of these two effects can dominate, depending on parameter values.

\section{Proposition 5 There exist economies in $\Phi^{N}$ that are not in $\Phi^{B}$ and vice versa.}

This result is demonstrated in Figure 3, which adds the set $\Phi^{N}$ to Figure 2. Focus first on panel (b) in the figure. When $q$ is small, the threshold value of $\theta$ for fragility to arise in this panel is much lower under a no-bailouts policy. Economies in the medium-shaded region on the left side of the graph are not fragile under the bailouts regime but become fragile when a no-bailouts policy is adopted. To understand why, note that when a crisis is unlikely, the incentive distortion associated with the bailouts regime is small and, as a result, the initial payment on early withdrawals $\left(c_{1}\right)$ is similar under the two different regimes. However, the payoff from staying invested in the event of a run $\left(c_{2 \beta}\right)$ is much lower under a no-bailouts policy because intermediaries receive no transfer from the public sector. As a result, impatient investors have a stronger incentive to withdraw early in state $\beta$ under the no-bailouts regime, which translates into a lower threshold value for $\theta$. The magnitude of this effect depends on the size of the bailout payments $b^{j}$, which depend in turn on the tax revenue collected by the policy maker in period 0 . When the parameter $\delta$ is close to zero, as in panel (a), the policy maker collects little tax revenue, bailout payments are small, and the threshold value of $\theta$ is only slightly lower under a no-bailouts policy. When $\delta$ is large, as in panel (c), the policy maker collects more tax revenue and bailouts payments are much larger, which implies that eliminating these bailouts lowers the threshold for fragility substantially.

As the probability of a crisis increases, the incentive distortion that causes the threshold value for $\theta$ to fall under the bailouts regime no longer appears. Instead, intermediaries operating under a no-bailouts policy become more cautious as $q$ increases and the threshold actually increases slightly with $q$. Moreover, the set $\Phi^{N}$ is independent of $\delta$ and thus the same in all three panels 


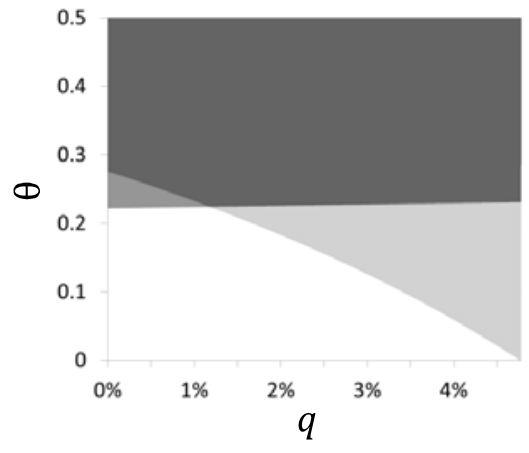

(a) $\delta=10^{-5}$

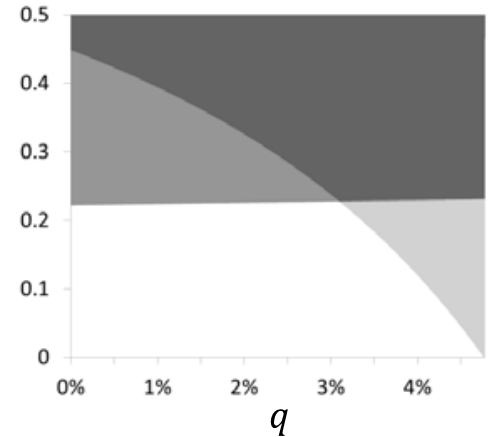

(b) $\delta=1$

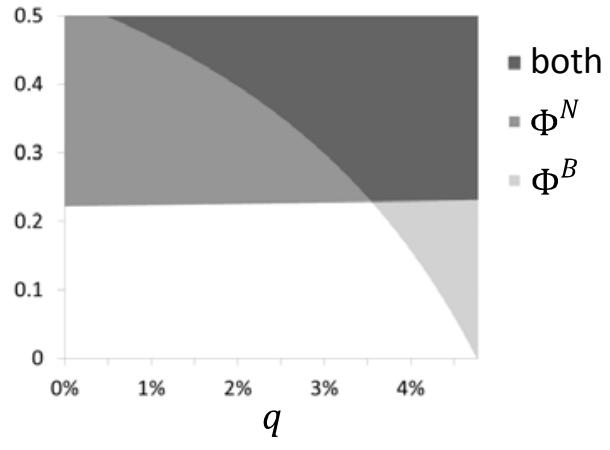

(c) $\delta=10$

Figure 3: Comparing the sets $\Phi^{B}$ and $\Phi^{N}$

of the figure; the size of the public sector has no effect on investors' withdrawal incentives when bailout payments are not permitted. As shown in each panel, the no-bailouts policy will generate a higher threshold for fragility when the probability of a crisis is large enough (above $\sim 3 \%$ in panel (b), for example). For economies in the lightly-shaded region in the lower right-hand corner of each panel, a no-bailouts policy eliminates the run equilibrium and thus promotes financial stability.

To summarize, Figure 3 illustrates the two competiting effects of a no-bailouts policy on financial stability. First, the policy leads intermediaries to become more liquid, which by itself would tend to raise the threshold level of $\theta$ and make the financial system more stable. The magnitude of this effect is small when $q$ is close to zero, but becomes large as $q$ increases. Second, the nobailouts policy makes investors more anxious to withdraw in state $\beta$ because their payoffs are more sensitive to the withdrawal behavior of others. The magnitude of this effect is largely independent of $q$, since withdrawal decisions are made after investors have observed realized state. In each panel of the figure, the first effect dominates when $q$ is large enough, while the second effect dominates when $q$ is smaller. Comparing across panels shows that the second effect becomes relatively more important when the public sector is large and the policy maker chooses bailout payments that significantly increase investors’ private consumption.

\subsection{Welfare comparison}

When the financial system is fragile under one policy regime but not the other, the optimal policy is clear: selecting the non-fragile regime will ensure that no run occurs and the first-best allocation of resources will obtain in both states. If the financial system is fragile under both policy regimes, the policy maker must compare the welfare levels $W^{B}$ and $W^{N}$ associated with the run equilibrium allocation in each case. In general, welfare may be higher under either regime, depending on 
parameter values. Once again, two competing effects are at work. Bailouts distort incentives and lead intermediaries to allocate too much consumption to the first fraction $\theta$ of investors who withdraw. Prohibiting bailouts removes this distortion, but also prevents socially-desirable risk sharing between the public and private sectors. The next proposition shows that when $q$ is small enough, the second effect always has a larger impact on welfare.

Proposition 6 For any $(R, \pi, \theta, u, v)$, there exists $\bar{q}>0$ such that $q<\bar{q}$ and $e \in \Phi^{B}$ implies both $e \in \Phi^{N}$ and $W^{N}<W^{B}$.

This result shows that when the probability of a crisis is sufficiently low, adopting a no-bailouts policy does not improve financial stability and necessarily lowers welfare.

Figure 4 plots the welfare gain from adopting a no-bailouts policy as a function of the probability of state $\beta$ for the same parameter values used above and setting $\theta=\delta=1 / 2$. When $q=0$, the crisis state never occurs and both policies deliver the first-best allocation; the benefit of switching regimes is zero. As $q$ increases, the no-bailouts regime initially lowers welfare, as established in Proposition 6. For higher values of $q$, however, the effects of the incentive distortion caused by bailouts become more pronounced and the pattern begins to reverse. Beyond approximately $q=3.5 \%$, adopting a no-bailouts policy would raise welfare in this economy.

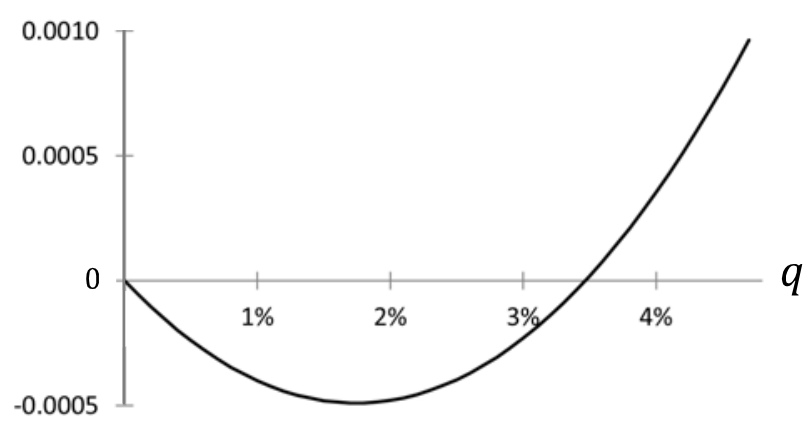

Figure 4: Welfare gain from a no-bailouts policy

These results demonstrate that prohibiting bailouts is at best an imperfect solution to the problems associated with distorted incentives and is sometimes worse than the distortions it aims to correct. In the next section, I study a policy regime in which bailouts are allowed and the policy maker takes a Pigouvian approach to correcting the resulting distortions. I show how this approach can both generate higher welfare and improve financial stability relative to either of the policy regimes studied so far. 


\section{Taxing Short-term Liabilities}

Suppose now that instead of restricting bailouts, the policy maker is given an additional policy tool: a Pigouvian tax on intermediaries' short-term liabilities. Specifically, at point $(a)$ in Figure 1 , the policy maker also chooses a fee $\eta$ that is imposed on all funds withdrawn from the banking system before the state is revealed. ${ }^{12}$ When each of the first fraction $\theta$ of investors withdraws from intermediary $j$ and receives $c_{1}^{j}$, the intermediary must also pay an amount $\eta c_{1}^{j}$ to the policy maker. As discussed above, $\theta c_{1}^{j}$ can be interpreted as the value of an intermediary's short-term liabilities per investor and, hence, $\eta$ represents the Pigouvian tax rate on these liabilities. To facilitate comparison with the earlier cases, I make the policy revenue neutral by giving each intermediary a lump-sum transfer equal to the average fee collected per investor,

$$
N=\eta \theta \bar{c}_{1}
$$

How does this additional policy tool change equilibrium outcomes? To answer this question, I again work backward through the decisions in Figure 1. Decisions $(d)$ and $(c)$ are the same as under the bailouts regime in Section 3, meaning that intermediaries will allocate their remaining resources to solve (3) and the policy maker will choose the bailouts payments $\left\{b^{j}\right\}$ to satisfy conditions (6) and (7). This bailout policy now implies that the resources $\psi_{\beta}^{j}$ available to intermediary $j$ in the run state are equal to

$$
\psi_{\beta}^{j}=1-\tau-\theta(1+\eta) \bar{c}_{1}+N+b,
$$

which, using the rebate policy in (22), reduces to expression (8) from the earlier section. Since the fee $\eta$ does not change the total quantity of resources available for private consumption, it will not affect an individual intermediary's resources in state $\beta$ after bailout payments have been made.

\subsection{Modified incentives}

We can write decision $(b)$ in Figure 1 for intermediary $j$ as the problem of choosing $c_{1}^{j}$ to maximize

$$
\theta u\left(c_{1}^{j}\right)+(1-q) V\left(1-\tau-\theta(1+\eta) c_{1}^{j}+N ; \widehat{\pi}_{\alpha}\right)+q V\left(1-\tau-\theta \bar{c}_{1}+b ; \widehat{\pi}_{\beta}\right) .
$$

The middle term in this expression shows how each unit of resources given to the first fraction $\theta$ of

$12 \quad$ The fee $\eta$ could equivalently be chosen at point $(b)$ in Figure 1, immediately before each withdrawal takes place. The key timing assumption is that $\eta$ is determined after investors have returned to isolation in period 0 and before intermediaries choose $c_{1}^{j}$ in period 1 . 
investors who withdraw now reduces the funds available for the intermediary's remaining investors in state $\alpha$ by $(1+\eta)$. The first-order condition characterizing the solution to this problem is

$$
u^{\prime}\left(c_{1}^{j}\right)=(1+\eta)(1-q) \mu_{\alpha}
$$

This condition implicitly defines the intermediary's optimal choice of $c_{1}^{j}$ as a function of both the tax rate $\tau$ on deposits and the fee $\eta$ on short-term liabilities.

In decision $(a)$, the policy maker chooses $\tau$ and $\eta$ to maximize ex ante welfare. Using the rebate policy in (22), this problem reduces to maximizing the objective function in (12) subject to the constraints (13) - (15), but with $c_{1}$ and $b$ now as functions of both $\tau$ and $\eta$ rather than $\tau$ alone. The first-order condition for $\eta$ is

$$
\left(u^{\prime}\left(c_{1}\right)-(1-q) \mu_{\alpha}-q \mu_{\beta}\right) \theta \frac{d c_{1}}{d \eta}=-q\left[\mu_{\beta}-v^{\prime}(\tau-b)\right] \frac{d b}{d \eta} .
$$

Because the policy maker will choose the size of the bailout package in decision $(c)$ according to (6), the right-hand side of this expression is zero. The fee $\eta$ will, therefore, be chosen to make the left-hand side zero, which requires

$$
u^{\prime}\left(c_{1}\right)=(1-q) \mu_{\alpha}+q \mu_{\beta} .
$$

Recall that the incentive distortion created by the bailout policy leads intermediaries to undervalue resources paid out before the state is revealed because they (rationally) ignore the consequences of these actions in state $\beta$, as shown in (10). The fee $\eta$ increases an intermediary's cost of using these resources, as shown in (23). How much does the policy maker want to increase this cost? Until the marginal value an intermediary assigns to these resources is equal to the expected future marginal utility of consumption, as shown in (24).

The first-order condition for the choice of $\tau$ is again given by (16). Using (6) and (24), the condition simplifies in this case to

$$
v^{\prime}(\tau)=\mu_{\alpha}
$$

When there was no Pigouvian tax, the policy maker used the tax on deposits to partially offset the distortion caused by the bailout policy, as shown in (17). Now that $\eta$ is used to correct this distortion, equation (25) shows that the policy maker will choose $\tau$ according to a standard Samuelson condition, equating the marginal values of public and private consumption in the state where no bailouts occur. 
Let $\mathbf{c}^{*}$ denote the allocation vector characterized by equations (4) - (6), (13) - (15), (24) and (25), which summarizes the best responses of intermediaries and the policy maker to the strategy profile (1) under the Pigouvian regime. The value of the fee $\eta$ in this allocation can be determined by combining (23) and (24) to obtain

$$
\eta^{*}=\frac{q \mu_{\beta}^{*}}{(1-q) \mu_{\alpha}^{*}} .
$$

If the probability of a crisis were zero, no incentive distortion would arise and the policy maker would set $\eta$ to zero. Higher values of $q$ create larger distortions, which leads the policy maker to choose a higher fee. Note that the objective of this policy is not to make intermediaries pay for bailouts. In general, the revenue raised by $\eta^{*}$ will not equal the size of the bailout package $b^{*}$, either in full or in expected value. ${ }^{13}$ Instead, the objective is to impose a marginal cost on each intermediary equal to the external effect of its actions in state $\beta$.

\subsection{Illiquidity}

How does the allocation vector $\mathbf{c}^{*}$ compare with those derived under the previous policy regimes? The next proposition shows that the Pigouvian approach reduces the degree of illiquidity in the financial system relative to the bailouts regime, but not as much as a no-bailouts policy does.

Proposition $7 \rho^{N}<\rho^{*}<\rho^{B}$ holds for all $q>0$.

It is straightforward to see why $\rho^{*}<\rho^{B}$ holds: the introduction of the Pigouvian tax raises the cost of giving consumption to investors who withdraw before the state is revealed, which leads intermediaries to become more conservative in setting $c_{1}$. The comparison of $\rho^{*}$ with $\rho^{N}$ is more subtle. Equation (24) shows that the policy maker will choose $\eta^{*}$ so that intermediaries equate the marginal value of private consumption before the state is revealed to the expected future marginal value of private consumption, exactly as they do under the no-bailouts policy in equation (19). However, these private consumption levels are different under the two regimes, especially in state $\beta$. Because the Pigouvian regime permits bailouts, the consumption levels $\left(c_{1 \beta}, c_{2 \beta}\right)$ are higher and, hence, the marginal value of this consumption, $\mu_{\beta}$, is lower than under a no-bailouts policy. As a result, intermediaries will be less conservative in setting $c_{1}$ under the Pigouvian regime. In other words, the partial insurance offered by bailouts leads intermediaries to become more illiquid

13 A stark way to see this point is to note that specifying the fee as $\eta^{*}\left(c_{1}^{j}-c_{1}^{*}\right)$ would lead to the same outcome but yield zero revenue. 
than under a no-bailouts policy, even when the incentive distortions associated with the bailouts are fully corrected by a Pigouvian tax.

\subsection{Fragility}

As with the previous regimes, the condition for financial fragility can be stated in terms of the properties of the allocation vector $\mathbf{c}^{*}$. This result is established in the following proposition, the proof of which follows those of Propositions 1 and 3 closely and is omitted.

Proposition 8 The financial system is fragile under the policy regime with bailouts and a Pigouvian tax on short-term liabilities if and only if $c_{1}^{*} \geq c_{2 \beta}^{*}$ holds.

Let $\Phi^{*}$ denote set of economies $e$ that are fragile under the Pigouvian regime. The next proposition shows that this regime is unambiguously better for financial stability than the previous regimes.

Proposition 9 The set $\Phi^{*}$ is strictly contained in both $\Phi^{B}$ and $\Phi^{N}$.

This result is illustrated in Figure 5, where $\Phi^{*}$ corresponds to the darkest area at the top of panels (a) and (b). When the probability of a crisis is close to zero, the incentive distortion created by bailouts is small and the allocations $c^{*}$ and $c^{B}$ are nearly identical. In the limit as $q$ goes to zero, therefore, the threshold value for $\theta$ above which fragility obtains is the same for the sets $\Phi^{*}$ and $\Phi^{B}$. As $q$ increases, however, the policy maker now uses the fee $\eta^{*}$ to correct the incentive distortion that arises under the bailouts regime. As a result, the threshold value for $\theta$ no longer declines with $q$ as in the set $\Phi^{B}$, but now increases slightly as the higher probability of a crisis raises the expected marginal value of consumption. For larger values of $q$, the combination of bailouts and a Pigouvian tax thus generates a substantially higher threshold for fragility than the policy regime with bailouts alone. In panel (c), where the public sector is relatively large, the financial system is never fragile under the Pigouvian regime.

The figure also shows the threshold value for $\theta$ to be higher under the Pigouvian regime than under a no-bailouts policy for any value of $q$. To understand why, consider first the case where $q$ is close to zero. In this case, the payments made to the first fraction $\theta$ of investors to withdraw, $c_{1}^{*}$ and $c_{1}^{N}$, are nearly identical under the two regimes, but the payments made to the remaining patient investors in the crisis state, $c_{2 \beta}^{*}$ and $c_{2 \beta}^{N}$, are not. Under the Pigouvian regime, the bailouts payments raise $c_{2 \beta}^{*}$, which has the effect of decreasing the incentive for patient investors to run. When $q$ is larger, the payments $c_{1}^{*}$ and $c_{1}^{N}$ begin to diverge as the policy maker sets the tax rate 


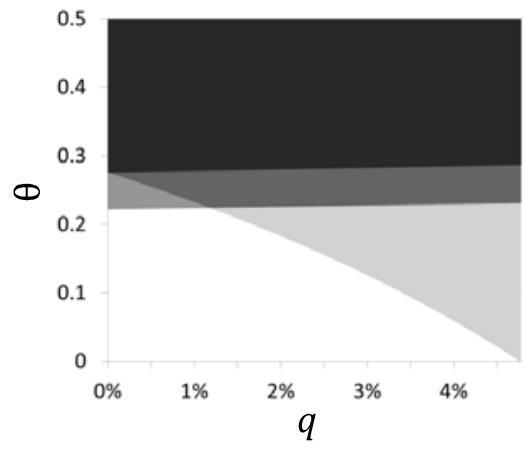

(a) $\delta=10^{-5}$

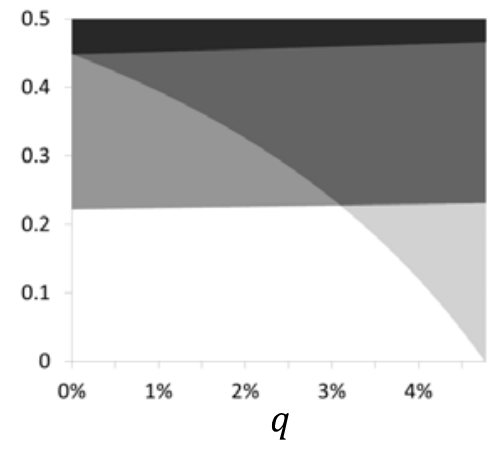

(b) $\delta=1$

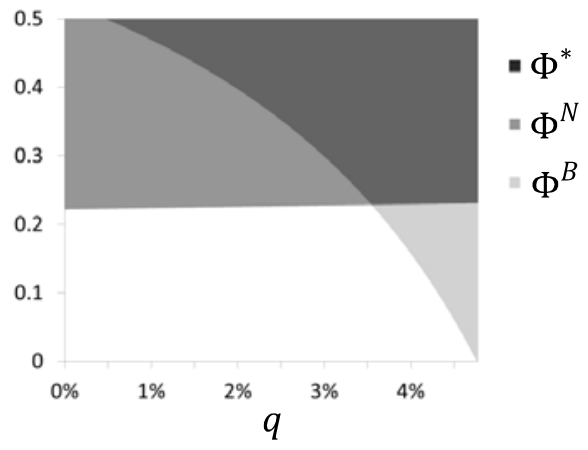

(c) $\delta=10$

Figure 5: $\Phi^{*}$ is strictly contained in both $\Phi^{D}$ and $\Phi^{N B}$

$\tau$ differently in the two regimes, but the same basic effect is present. In particular, by permitting bailouts payments to mitigate investors' losses in state $\beta$, the Pigouvian regime decreases a patient investor's incentive to run relative to a no-bailouts policy. The magnitude of this effect depends on the size of the bailout payments which, in turn, depends on the amount of resources available to the policy maker. The gain in financial stability from adopting the Pigouvian regime instead of a no-bailouts policy is small when $\delta$ is close to zero and the policy maker sets the tax rate $\tau$ very low, but becomes much more significant for higher values of $\delta$.

It is worth noting that the set-theoretic approach to measuring fragility used here has a natural interpretation in terms of changes in the probability of a financial crisis. Suppose that at the beginning of period zero, the parameter values $e$ are drawn at random from some probability distribution $f$. If the realized $e$ is such that the economy is not fragile, investors do not run on the financial system in either state. If the economy is fragile, however, investors follow the strategy profile (1). The ex ante probability assigned to a crisis by this process will be strictly lower under the Pigouvian regime than under either of the other regimes for any probability distribution $f$ that has full support. In this sense, Proposition 9 can be interpreted as saying that adopting the Pigouvian regime makes a financial crisis less likely to occur. ${ }^{14}$

\footnotetext{
14 An alternative approach to determining the probability of a financial crisis would be to attempt to resolve the multiplicity of equilibrium by introducing private information as in the literature on global games pioneered by Carlsson and van Damme (1993). However, this approach places rather strict requirements on the information structure of the model. Papers that have used the global games methodology in Diamond-Dybvig type models have done so by placing arbitrary restrictions on contracts between intermediaries and their investors (see, for example, Rochet and Vives, 2004, and Goldstein and Pauzner, 2005). These restrictions themselves are potential sources of financial fragility, quite separate from the issues related to bailouts under consideration here. The approach taken here captures the effects of changes in the incentives faced by investors in a reasonably clear and transparent way, and does not place any restrictions on financial arrangements other than those imposed by the physical environment.
} 


\subsection{Welfare}

For an economy outside of the set $\Phi^{*}$, the optimal policy is clear: choosing the Pigouvian regime ensures that the financial system is not fragile and will generate the first-best allocation of resources in both states. For an economy in the set $\Phi^{*}$, Proposition 9 shows it will be fragile under all three policy regimes and, hence, the best regime is the one that generates the highest level of welfare $W$ in the run equilibrium. The next proposition establishes that the Pigouvian regime is always best.

Proposition 10 For any $e \in \Phi^{*}$ with $q>0, W^{*}>\max \left\{W^{B}, W^{N}\right\}$.

Compared to the bailouts-only policy, the Pigouvian regime raises welfare by correcting the distortion that leads intermediaries to allocate too much consumption to the first fraction $\theta$ of investors who withdraw. In particular, the equilibrium fee $\eta^{*}$ induces intermediaries to equate the marginal value of consumption for these investors with the expected marginal value of consumption of the remaining investors, as shown in (24). Relative to a no-bailouts policy, the Pigouvian regime raises welfare by allowing the risk associated with financial crises to be shared by the pubic and private sectors. Whereas a no-bailouts policy requires that all of the losses associated with a crisis fall on the private consumption of the remaining investors, under the Pigouvian regime these losses are divided between private and public consumption according to condition (6).

In this way, the Pigouvian regime combines the desirable features of each of the previous two regimes: it allows the socially-efficient risk sharing of the bailouts regime, but maintains proper incentives for intermediaries as in the no-bailouts regime. In fact, the Pigouvian regime generates the welfare-maximizing allocation of resources conditional on the behavior of depositors specified in (1). If a benevolent social planner controlled both the financial system and the public sector, but not investors' withdrawal decisions, the allocation of resources she would choose in response to the strategy profile (1) is exactly $c^{*}$.

Taken together, Propositions 9 and 10 demonstrate that taxing short-term liabilities can be a powerful policy tool: it both improves the allocation of resources and brings the macroprudential benefit of lower financial fragility. Implementing such a tax raises a number of issues that are beyond the scope of the present paper, such as how short-term liabilities should be measured in practice and how the optimal tax rate can be determined. It is worth noting, however, that current policy efforts are addressing many of these issues. For example, the Basel III accords introduce a new framework for liquidity regulation that includes a methodology for measuring of an interme- 
diary's projected net cash outflows during a 30-day period of financial stress (see BCBS, 2013). This measure corresponds closely to the term $\theta c_{1}^{j}$ in the model - the amount of funds that will flow out of the institution before the intermediary and policy maker are able to react - which is the appropriate base for the Pigouvian tax. Stein (2013) discusses how the regulatory tools created as part of this framework act as a tax the activity of maturity transformation and thus have the same effect on incentives as the fee $\eta$ used here. ${ }^{15}$ Kocherlakota (2010) suggests that the government could sell "rescue bonds" that pay off when one or more institutions is bailed out; the prices of these bonds could then be used to estimate the probability of a crisis, which is a key determinant of the optimal tax rate $\eta^{*}$ in (26). The results in this section highlight the importance of these and related efforts to develop improved regulatory and prudential policy tools.

\section{Concluding Remarks}

The idea that bailouts can significantly distort the incentives of financial institutions and their investors has figured prominently in recent policy debates. One popular view holds that the best way to deal with this problem is to restrict policy makers from engaging in future bailouts wherever possible. To evaluate this proposition, I have presented a model with three key features: $(i)$ when there is aggregate risk in the economy, it is efficient for some of this risk to be borne by the public sector, $(i i)$ the anticipation of being bailed out in the event of a crisis distorts the incentives of financial intermediaries, and ( iii) investors are more likely to withdraw from the financial system when the potential loss they face in a crisis is larger. These features arise naturally in the environment I study here, which consists of fairly standard components, and seem likely to appear in a wide range of related settings.

It follows immediately from $(i)$ that a strict no-bailouts policy cannot achieve an efficient allocation of resources in such a setting. If some risk should be borne by the public sector, achieving an efficient outcome requires allowing the policy maker to engage in bailouts if a crisis occurs. If bailouts are permitted, (ii) implies that policy makers should use prudential policy measures to offset the resulting distortion in incentives. In Section 5, I showed how placing a tax on intermediaries' short-term liabilities - and no restrictions on the bailout policy - is strictly better than

\footnotetext{
15 Stein (2013) also discusses the distinction between price-based and quantity-based regulation in the context of the new liquidity regulations. In the environment studied here, the policy maker could achieve the same outcome using either the Pigouvian tax at rate $\eta^{*}$ or by directly mandating that the quantity of consumption given to the first $\theta$ investors who withdraw be $c_{1}^{*}$. In a setting where some characteristics of banks are unobserved by the policy maker, the outcomes under price-based and quantity-based regulation are generally different. See also Perotti and Suarez (2011).
} 
adopting a no-bailouts policy: it generates higher welfare and a more stable financial system.

Proponents of the no-bailouts view may argue, however, that this result relies too heavily on the ability of policy makers and regulators to design and maintain an effective prudential policy regime. In practice, using taxes or other regulatory tools to precisely set incentives can be difficult. Intermediaries may, for example, have incentives to devise new types of liabilities or funding structures for which the appropriate regulatory treatment is not immediately clear. In a world where effectively controlling incentives through taxes/regulation is infeasible, one might be tempted to view a no-bailouts policy as at least representing a step in the right direction.

The primary message of the paper is that this view is often incorrect. The analysis highlights two important costs that limit the attractiveness of a no-bailouts policy. The first is a consequence of $(i)$ : by inefficiently concentrating all risk in the private sector, eliminating bailouts makes intermediaries too cautious from a social point of view and leads to an underprovision of financial services. Moreover, (iii) implies that removing the insurance provided by bailouts will tend to increase the susceptibility of the financial system to a crisis by making investors more prone to run at the first sign of trouble. In Section 4, I showed how adopting a no-bailouts policy can make investors strictly worse off by both lowering equilibrium welfare and making the financial system more fragile. In other words, the costs associated with a no-bailouts policy will, in many cases, outweigh the benefits.

It should be emphasized that the bailout policies studied here are efficient; they do not lead to rent-seeking behavior, nor are they motivated by outside political considerations. In reality, these types of distortions are important concerns. The message of the paper is not that any type of bailout policy is acceptable; limits on the ability of policy makers to undertake some types of redistribution during a crisis may well be desirable. Rather, the message is that restrictions on bailouts alone cannot ensure that intermediaries and investors face the correct ex ante incentives. The results thus highlight the importance of efforts, many of which are currently underway, to develop improved regulatory and other prudential policy tools. 


\section{Appendix A. Proofs of Selected Propositions}

Proposition 1: The financial system is fragile under the bailouts regime if and only if (18) holds.

Proof: The discussion in the text establishes that (18) is a sufficient condition for the financial system to be fragile, since it guarantees there exists an equilibrium in which investors follow strategy profile (1). What remains to be proven is that this condition is also necessary for fragility to arise.

To begin, note that any equilibrium strategy profile must satisfy two basic properties. First, all impatient investors must withdraw in period 1 , since they receive no utility from consuming in period 2. Second, because (5) implies that intermediaries' best response to any strategy profile satisfies $c_{1 s}<c_{2 s}$ in both states, all period-1 withdrawals that occur after intermediaries have observed the state must be made by impatient investors. For any strategy profile satisfying these two properties, let $\varepsilon_{s} \in[0,1-\pi]$ denote the fraction of the first $\theta$ withdrawals that are made by patient investors. (Note that (1) corresponds to the profile with $\varepsilon_{\alpha}=0$ and $\varepsilon_{\beta}=1-\pi$.) Definition 1 states that the financial system is fragile if there exists an equilibrium in which investors follow some strategy profile with $\varepsilon_{\beta}>0$. I will show that whenever such an equilibrium exists, condition (18) holds.

Let $\widetilde{y}$ be any such strategy profile and let $\widetilde{\mathbf{c}}$ denote the allocation generated by the best responses of intermediaries and the policy maker to this profile. This allocation is characterized by equations (4) - (6), (10), (13) - (15) and (17), where the fraction of remaining investors who are impatient after $\theta$ withdrawals have been made, $\widehat{\pi}_{s}$, is now given by

$$
\widehat{\pi}\left(\varepsilon_{s}\right)=\frac{\pi-\theta\left(1-\varepsilon_{s}\right)}{1-\theta} \text { for } s=\alpha, \beta,
$$

which is strictly increasing in the size of the run $\varepsilon_{s}$. If there is an equilibrium in which investors follow $\widetilde{y}$, it must be the case that $\widetilde{\mathbf{c}}$ satisfies

$$
\widetilde{c}_{1} \geq \widetilde{c}_{2 \beta}
$$

that is, the patient investors who withdraw early in state $\beta$ would not benefit by deviating and withdrawing in period 2 . To establish that (18) is a necessary condition for fragility, therefore, it suffices to show that whenever (27) holds for some $\widetilde{y}$, (18) also holds.

We can further limit the set of candidate strategy profiles $\widetilde{y}$ by noting that the restriction on 
parameter values in (11) can be written as $(1-q)>1 / R$, which clearly implies

$$
(1-q) \widetilde{\mu}_{\alpha}>\frac{\widetilde{\mu}_{\alpha}}{R}
$$

Combined with (5) and (10), this inequality implies $u^{\prime}\left(\widetilde{c}_{1}\right)>u^{\prime}\left(\widetilde{c}_{2 \alpha}\right)$ and thus $\widetilde{c}_{1}<\widetilde{c}_{2 \alpha}$, which demonstrates that under the best-response allocation $\widetilde{\mathbf{c}}$, all patient investors strictly prefer to wait until period 2 to withdraw in state $\alpha$. We can, therefore, limit our attention to strategy profiles $\widetilde{y}$ with $\varepsilon_{\alpha}=0$.

Since the function $u$ exhibits constant relative risk aversion, expected utility preferences over pairs $\left(c_{1 s}, c_{2 s}\right)$ are homothetic and the solution to (3) satisfies the linear relationship

$$
c_{2 s}=R^{\frac{1}{\gamma}} c_{1 s}
$$

where $\gamma>1$ is the coefficient of relative risk aversion. Using the definitions of $\psi_{s}$ in (13) - (14) together with (4), (15) and (28), we can write the resource constraint for each state $s$ as

$$
\theta c_{1}+\left[(1-\theta)\left(\widehat{\pi}\left(\varepsilon_{s}\right) R^{\frac{\gamma-1}{\gamma}}+1-\widehat{\pi}\left(\varepsilon_{s}\right)\right)\right] \frac{c_{2 s}}{R}+g_{s}=1
$$

Since $R$ and $\gamma$ are both greater than unity, the term in square brackets is strictly increasing in $\varepsilon_{s}$.

The remainder of the proof proceeds in three steps. First, I show that the shadow value of resources in state $\alpha$ is lower under $\widetilde{\mathbf{c}}$ than under $\mathbf{c}^{B}$. I then show that the same is true in state $\beta$. Finally, I show how these two preliminary results combine to establish the proposition.

Step 1: Show $\widetilde{\mu}_{\alpha} \leq \mu_{\alpha}^{B}$. This step of the proof is by contradiction. Suppose that $\widetilde{\mu}_{\alpha}>\mu_{\alpha}^{B}$ held. Then (5) and (10) would imply

$$
\widetilde{c}_{1}<c_{1}^{B} \quad \text { and } \quad \widetilde{c}_{2 \alpha}<c_{2 \alpha}^{B}
$$

Using the resource constraint (29) in state $\alpha$ with $\varepsilon_{\alpha}=0$ for both strategy profiles, these inequalities would imply $\widetilde{g}_{\alpha}>g_{\alpha}^{B}$. Equation (17) and the relationship $\tau=g_{\alpha}$ would then imply

$$
\widetilde{\mu}_{\alpha}+\frac{q}{1-q} \widetilde{\mu}_{\beta} \theta \frac{d c_{1}}{d \tau}<\mu_{\alpha}^{B}+\frac{q}{1-q} \mu_{\beta}^{B} \theta \frac{d c_{1}}{d \tau}
$$

Since $\widetilde{\mu}_{\alpha}>\mu_{\alpha}^{B}$ is assumed to hold and the derivative $d c_{1} / d \tau$ is negative (and the same under both allocations), this expression would imply $\widetilde{\mu}_{\beta}>\mu_{\beta}^{B}$. However, (5) and (6), together with the 
relationship $g_{\beta}=\tau-b$, would then imply

$$
\widetilde{c}_{2 \beta}<c_{2 \beta}^{B} \quad \text { and } \quad \widetilde{g}_{\beta}<g_{\beta}^{B} .
$$

Using $\varepsilon_{\beta} \leq 1-\pi$, we would then have

$$
\begin{aligned}
& (1-\theta)\left(\widehat{\pi}\left(\varepsilon_{\beta}\right) R^{\frac{\gamma-1}{\gamma}}+1-\widehat{\pi}\left(\varepsilon_{\beta}\right)\right) \frac{\widetilde{c}_{2 \beta}}{R}+\widetilde{g}_{\beta} \\
< & (1-\theta)\left(\widehat{\pi}(1-\pi) R^{\frac{\gamma-1}{\gamma}}+1-\widehat{\pi}(1-\pi)\right) \frac{c_{2 \beta}^{B}}{R}+g_{\beta}^{B},
\end{aligned}
$$

which, using the resource constraint (29) in state $\beta$, would yield $\widetilde{c}_{1}>c_{1}^{B}$, contradicting (30) above. Therefore, $\widetilde{\mu}_{\alpha} \leq \mu_{\alpha}^{B}$ must hold.

Step 2: Show $\widetilde{\mu}_{\beta} \leq \mu_{\beta}^{B}$. The result from step 1, together with (5) and (10), implies both $\widetilde{c}_{1} \geq c_{1}^{B}$ and $\widetilde{c}_{2 \alpha} \geq c_{2 \alpha}^{B}$. The resource constraint (29) in state $\alpha$ then implies

$$
\widetilde{g}_{\alpha} \leq g_{\alpha}^{B}
$$

which, combined with (17), yields

$$
\widetilde{\mu}_{\alpha}+\frac{q}{1-q} \widetilde{\mu}_{\beta} \theta \frac{d c_{1}}{d \tau} \geq \mu_{\alpha}^{B}+\frac{q}{1-q} \mu_{\beta}^{B} \theta \frac{d c_{1}}{d \tau} .
$$

Since $\widetilde{\mu}_{\alpha} \leq \mu_{\alpha}^{B}$ holds and the derivative $d c_{1} / d \tau$ is negative (and the same under both allocations), this expression implies $\widetilde{\mu}_{\beta} \leq \mu_{\beta}^{B}$, as desired.

Step 3: Show that $\widetilde{c}_{1} \geq \widetilde{c}_{2 \beta}$ implies (18). The previous step shows how $\widetilde{\mu}_{\alpha} \leq \mu_{\alpha}^{B}$ implies (31) and thus

$$
v^{\prime}\left(\widetilde{g}_{\alpha}\right) \geq v^{\prime}\left(g_{\alpha}^{B}\right)
$$

Also, using (6), the result from step 2 that $\widetilde{\mu}_{\beta} \leq \mu_{\beta}^{B}$ holds implies that we have $\widetilde{g}_{\beta} \geq g_{\beta}^{B}$ and thus

$$
v^{\prime}\left(\widetilde{g}_{\beta}\right) \leq v^{\prime}\left(g_{\beta}^{B}\right) .
$$

Combining these two inequalities yields

$$
\frac{v^{\prime}\left(\widetilde{g}_{\alpha}\right)}{v^{\prime}\left(\widetilde{g}_{\beta}\right)} \geq \frac{v^{\prime}\left(g_{\alpha}^{B}\right)}{v^{\prime}\left(g_{\beta}^{B}\right)} .
$$


Using (6) and (17), we then have

$$
\frac{\widetilde{\mu}_{\alpha}+\frac{q}{1-q} \widetilde{\mu}_{\beta} \theta \frac{d c_{1}}{d \tau}}{\widetilde{\mu}_{\beta}} \geq \frac{\mu_{\alpha}^{B}+\frac{q}{1-q} \mu_{\beta}^{B} \theta \frac{d c_{1}}{d \tau}}{\mu_{\beta}^{B}}
$$

or, again using the fact that the derivative $d c_{1} / d \tau$ is the same under both allocations,

$$
\frac{\widetilde{\mu}_{\alpha}}{\widetilde{\mu}_{\beta}} \geq \frac{\mu_{\alpha}^{B}}{\mu_{\beta}^{B}}
$$

Together with (5) and (10), this inequality implies

$$
\frac{u^{\prime}\left(\widetilde{c}_{1}\right)}{u^{\prime}\left(\widetilde{c}_{2 \beta}\right)} \geq \frac{u^{\prime}\left(c_{1}^{B}\right)}{u^{\prime}\left(c_{2 \beta}^{B}\right)} .
$$

Using the homotheticity of preferences, we then have

$$
\frac{\widetilde{c}_{1}}{\widetilde{c}_{2 \beta}} \leq \frac{c_{1}^{B}}{c_{2 \beta}^{B}}
$$

It follows immediately from this inequality that (27) implies (18), as desired.

Proposition 2: For any $e \in \Phi^{B}$, we have $\left(c_{1 \beta}^{B}, c_{2 \beta}^{B}, g_{\beta}^{B}\right) \ll\left(c_{1 \alpha}^{B}, c_{2 \alpha}^{B}, g_{\alpha}^{B}\right)$.

Proof: Consider any economy in $\Phi^{B}$. Condition (11) can be written as

$$
(1-q) \mu_{\alpha}^{B}>\frac{1}{R} \mu_{\alpha}^{B}
$$

which, together with (5) and (10), implies $u^{\prime}\left(c_{1}^{B}\right)>u^{\prime}\left(c_{2 \alpha}^{B}\right)$. Combining this inequality with (18) yields $c_{2 \beta}^{B} \leq c_{1}^{B}<c_{2 \alpha}^{B}$. The first-order conditions in (5) then imply

$$
\mu_{\beta}^{B}>\mu_{\alpha}^{B} \quad \text { and } \quad c_{1 \beta}^{B}<c_{1 \alpha}^{B}
$$

which establishes that both elements of private consumption are smaller in state $\beta$ than in state $\alpha$.

To show that public consumption is also lower in state $\beta$, note that (17), together with the relationship $g_{\alpha}=\tau$ and the fact that the derivative $d c_{1} / d \tau$ is negative, implies

$$
v^{\prime}\left(g_{\alpha}^{B}\right)<\mu_{\alpha}^{B}
$$

Combining this result with the first inequality in (32) and equation (6) yields

$$
v^{\prime}\left(g_{\alpha}^{B}\right)<\mu_{\beta}^{B}=v^{\prime}\left(g_{\beta}^{B}\right)
$$


which immediately implies $g_{\beta}^{B}<g_{\alpha}^{B}$ and concludes the proof.

Proposition 4: $\rho^{N}<\rho^{B}$ holds for all $q>0$.

Proof: This result follows from Proposition 7, which is proved below.

Proposition 6: For any $(R, \pi, \theta, u, v)$, there exists $\bar{q}>0$ such that $q<\bar{q}$ and $e \in \Phi^{B}$ implies both $e \in \Phi^{N}$ and $W^{N}<W^{B}$.

Proof: First, note that using the definitions of $\psi_{s}$ in (13) - (14) together with (4), (15) and (28), we can write the resource constraint for each state $s$ as

$$
\theta c_{1}+\left[(1-\theta)\left(\widehat{\pi}_{s} R^{\frac{\gamma-1}{\gamma}}+1-\widehat{\pi}_{s}\right)\right] \frac{c_{2 s}}{R}+g_{s}=1
$$

For any $(R, \pi, \theta, u, v)$, we can consider the best-response allocations $\mathbf{c}^{B}$ and $\mathbf{c}^{N}$ as functions of the probability $q$. Note that, in the limit as $q$ goes to zero, conditions (10) and (19) become equivalent, as do conditions (17) and (21). Combined with (5) and (33) for $s=\alpha$, the convergence of these two pairs of conditions implies

$$
\lim _{q \rightarrow 0}\left(c_{1}^{N}(q), c_{1 \alpha}^{N}(q), c_{2 \alpha}^{N}(q), g_{\alpha}^{N}(q)\right)=\lim _{q \rightarrow 0}\left(c_{1}^{B}(q), c_{1 \alpha}^{B}(q), c_{2 \alpha}^{B}(q), g_{\alpha}^{B}(q)\right)
$$

Intuitively, as the probability of a crisis goes to zero, the effect of events in the crisis state on the allocation of resources in normal times disappears.

The allocation of resources in state $\beta$ remains different across regimes, however. In particular, public consumption in state $\beta$ is lower under the bailouts regime because some public funds are transferred to the intermediaries. This fact can be seen by combining (34) with the result $g_{\beta}^{B}<g_{\alpha}^{B}$ from Proposition 2 and the no-bailouts condition (20) to obtain

$$
\lim _{q \rightarrow 0} g_{\beta}^{N}(q)>\lim _{q \rightarrow 0} g_{\beta}^{B}(q)
$$

Looking at the resource constraint (33) for $s=\beta$, equations (34), (35) and the definitions of $\widehat{\pi}_{s}$ in (2) imply that in the limit as $q$ goes to zero, $c_{2 \beta}$ must be lower in the no-bailouts regime,

$$
\lim _{q \rightarrow 0} c_{2 \beta}^{N}(q)<\lim _{q \rightarrow 0} c_{2 \beta}^{B}(q)
$$


Together, this inequality and (34) imply that there exists some $\bar{q}>0$ such that

$$
\frac{c_{1}^{N}(q)}{c_{2 \beta}^{N}(q)}>\frac{c_{1}^{B}(q)}{c_{2 \beta}^{B}(q)} \quad \text { for all } q<\bar{q}
$$

For any $q<\bar{q}$, if $e \in \Phi^{B}$ then $c_{1}^{B}(q) \geq c_{2 \beta}^{B}(q)$ holds by definition. The inequality above then implies $c_{1}^{N}(q)>c_{2 \beta}^{N}(q)$ and, hence, $e \in \Phi^{N B}$ also holds, establishing the first part of the proposition.

For the second part of the proposition, note that (34) implies the welfare levels associated with the run equilibrium allocations under the two regimes converge as $q$ goes to zero,

$$
\lim _{q \rightarrow 0} W^{N}(q)=\lim _{q \rightarrow 0} W^{B}(q) .
$$

As $q$ approaches zero, both the incentive distortions and the welfare loss associated with a potential crisis disappear. The proposition will be established, therefore, if we can show that welfare initially falls faster under the no-bailouts regime as $q$ rises, that is, if we can show

$$
\lim _{q \rightarrow 0} \frac{d W^{N}(q)}{d q}<\lim _{q \rightarrow 0} \frac{d W^{B}(q)}{d q} .
$$

The derivative for the bailouts regime can be written as

$$
\lim _{q \rightarrow 0} \frac{d W^{B}(q)}{d q}=-V_{\alpha}\left(1-g_{\alpha}^{B}-\theta c_{1}^{B}\right)-v\left(g_{\alpha}^{B}\right)+V_{\beta}\left(1-g_{\beta}^{B}-\theta c_{1}^{B}\right)+v\left(g_{\beta}^{B}\right) .
$$

Using (34), we can write the corresponding derivative under a no-bailouts policy as

$$
\lim _{q \rightarrow 0} \frac{d W^{N}(q)}{d q}=-V_{\alpha}\left(1-g_{\alpha}^{B}-\theta c_{1}^{B}\right)-v\left(g_{\alpha}^{B}\right)+V_{\beta}\left(1-g_{\alpha}^{B}-\theta c_{1}^{B}\right)+v\left(g_{\alpha}^{B}\right) .
$$

Notice that the first two terms in these derivatives, which are based on the allocation of resources in state $\alpha$, are the same. The last two terms differ, however, because under a no-bailouts policy the level of the public good must be equal across states: $g_{\beta}^{N}=g_{\alpha}^{N}$. Both of these values converge to $g_{\alpha}^{B}$ as $q$ goes to zero, as indicated in the expression above.

The final step is to note that the bailout policy characterized by (6) sets the level of public consumption in state $\beta$ to maximize the sum of these last two terms. Since Proposition 2 establishes that $g_{\alpha}^{B} \neq g_{\beta}^{B}$, we must, therefore, have

$$
V_{\beta}\left(1-g_{\beta}^{B}-\theta c_{1}^{B}\right)+v\left(g_{\beta}^{B}\right)>V_{\beta}\left(1-g_{\alpha}^{B}-\theta c_{1}^{B}\right)+v\left(g_{\alpha}^{B}\right)
$$

and, hence, the inequality in (36) holds, as desired. 
Proposition 7: $\rho^{N}<\rho^{*}<\rho^{B}$ holds for all $q>0$.

Proof: We first establish $\rho^{*}<\rho^{B}$. Since the multipliers $\mu_{\alpha}^{*}$ and $\mu_{\beta}^{*}$ are always strictly positive, we clearly have

$$
(1-q)+q \frac{\mu_{\beta}^{*}}{\mu_{\alpha}^{*}}>(1-q)
$$

which can be rewritten as

$$
\frac{(1-q) \mu_{\alpha}^{*}+q \mu_{\beta}^{*}}{\mu_{\alpha}^{*}}>\frac{(1-q) \mu_{\alpha}^{B}}{\mu_{\alpha}^{B}} .
$$

Using (5), (10) and (19), this inequality implies

$$
\frac{u^{\prime}\left(c_{1}^{*}\right)}{u^{\prime}\left(c_{2 \alpha}^{*}\right)}>\frac{u^{\prime}\left(c_{1}^{B}\right)}{u^{\prime}\left(c_{2 \alpha}^{B}\right)} .
$$

Using the homotheticity of preferences over pairs $\left(c_{1}, c_{2 \alpha}\right)$, we then have

$$
\frac{c_{1}^{*}}{c_{2 \alpha}^{*}}<\frac{c_{1}^{B}}{c_{2 \alpha}^{B}}
$$

The resource constraint (33) for state $\alpha$ can be written as

$$
\rho^{-1}=\frac{1-g_{\alpha}}{\theta c_{1}}=1+\frac{(1-\theta)}{\theta}\left(\widehat{\pi}_{\alpha} R^{\frac{\gamma-1}{\gamma}}+1-\widehat{\pi}_{\alpha}\right) \frac{1}{R}\left(\frac{c_{2 \alpha}}{c_{1}}\right) .
$$

Using this equation, the inequality in (37) immediately implies implies $\rho^{*}<\rho^{B}$, as desired.

Next, we establish the first inequality in the proposition, $\rho^{N}<\rho^{*}$. An argument similar to that in the proof of Proposition 2 can be used to show $g_{\beta}^{*}<g_{\alpha}^{*}$ holds. Using the resource constraint (33) for each state, this inequality implies

$$
\left(\widehat{\pi}_{\beta} R^{\frac{\gamma-1}{\gamma}}+1-\widehat{\pi}_{\beta}\right) \frac{c_{2 \beta}^{*}}{R}>\left(\widehat{\pi}_{\alpha} R^{\frac{\gamma-1}{\gamma}}+1-\widehat{\pi}_{\alpha}\right) \frac{c_{2 \alpha}^{*}}{R}
$$

Under a no-bailout policy, $g_{\beta}^{N}=g_{\alpha}^{N}$ holds by definition and the resource constraints imply

$$
\left(\widehat{\pi}_{\beta} R^{\frac{\gamma-1}{\gamma}}+1-\widehat{\pi}_{\beta}\right) \frac{c_{2 \beta}^{N}}{R}=\left(\widehat{\pi}_{\alpha} R^{\frac{\gamma-1}{\gamma}}+1-\widehat{\pi}_{\alpha}\right) \frac{c_{2 \alpha}^{N}}{R}
$$

Combining these two relationships yields

$$
\frac{c_{2 \beta}^{*}}{c_{2 \alpha}^{*}}>\frac{c_{2 \beta}^{N}}{c_{2 \alpha}^{N}}
$$


which, by the homotheticity of preferences, implies

$$
\frac{u^{\prime}\left(c_{2 \beta}^{*}\right)}{u^{\prime}\left(c_{2 \alpha}^{*}\right)}<\frac{u^{\prime}\left(c_{2 \beta}^{N}\right)}{u^{\prime}\left(c_{2 \alpha}^{N}\right)} \quad \text { or } \quad \frac{\mu_{\beta}^{*}}{\mu_{\alpha}^{*}}<\frac{\mu_{\beta}^{N}}{\mu_{\alpha}^{N}}
$$

From the latter inequality, we clearly have

$$
(1-q)+q \frac{\mu_{\beta}^{*}}{\mu_{\alpha}^{*}}<(1-q)+q \frac{\mu_{\beta}^{N}}{\mu_{\alpha}^{N}},
$$

which can be rewritten as

$$
\frac{(1-q) \mu_{\alpha}^{*}+q \mu_{\beta}^{*}}{R^{-1} \mu_{\alpha}^{*}}<\frac{(1-q) \mu_{\alpha}^{N}+q \mu_{\beta}^{N}}{R^{-1} \mu_{\alpha}^{N B}} .
$$

Using (5), (10) and (19), we then have

$$
\frac{u^{\prime}\left(c_{1}^{*}\right)}{u^{\prime}\left(c_{2 \alpha}^{*}\right)}<\frac{u^{\prime}\left(c_{1}^{N}\right)}{u^{\prime}\left(c_{2 \alpha}^{N}\right)} .
$$

Again using the homotheticity of preferences, this last inequality implies

$$
\frac{c_{1}^{*}}{c_{2 \alpha}^{*}}>\frac{c_{1}^{N}}{c_{2 \alpha}^{N}}
$$

which, using (38), yields $\rho^{*}>\rho^{N}$, as desired.

Proposition 9: The set $\Phi^{*}$ is strictly contained in both $\Phi^{B}$ and $\Phi^{N}$.

Proof: The proof is divided into four steps.

Step 1: Derive bounds for the derivative $d c_{1}^{B} / d \tau$. Differentiating the resource constraint

$$
\theta c_{1}^{B}+(1-\theta)\left(\widehat{\pi}_{\alpha} R^{\frac{\gamma-1}{\gamma}}+1-\widehat{\pi}_{\alpha}\right) \frac{c_{2 \alpha}^{B}}{R}=1-\tau
$$

with respect to $\tau$ yields

$$
\theta \frac{d c_{1}^{B}}{d \tau}+(1-\theta)\left(\widehat{\pi}_{\alpha} R^{\frac{\gamma-1}{\gamma}}+1-\widehat{\pi}_{\alpha}\right) \frac{1}{R} \frac{d c_{2 \alpha}^{B}}{d \tau}=-1
$$

Next, combining (5) and (10), then differentiating with respect to $\tau$ yields

$$
\frac{d c_{2 \alpha}^{B}}{d \tau}=\frac{1}{1-q} \frac{u^{\prime \prime}\left(c_{1}^{B}\right)}{R u^{\prime \prime}\left(c_{2 \alpha}^{B}\right)} \frac{d c_{1}^{B}}{d \tau}
$$

Using (5), (10) and that fact that $u$ is of the constant relative risk aversion form, it is straightforward 
to show

$$
\frac{u^{\prime \prime}\left(c_{1}^{B}\right)}{R u^{\prime \prime}\left(c_{2 \alpha}^{B}\right)}=(1-q)^{\frac{\gamma+1}{\gamma}} R^{\frac{1}{\gamma}}
$$

Substituting this relationship and (41) into (40) and solving yields

$$
\frac{d c_{1}^{B}}{d \tau}=-\frac{1}{\theta+\chi}
$$

where

$$
\chi \equiv \frac{1-\theta}{1-q}\left(\widehat{\pi}_{\alpha}+\left(1-\widehat{\pi}_{\alpha}\right) R^{\frac{1-\gamma}{\gamma}}\right)(1-q)^{\frac{\gamma+1}{\gamma}}>0
$$

Note that $\chi>0$ implies the following bounds

$$
-1<\theta \frac{d c_{1}^{B}}{d \tau}<0
$$

Combined with (17), the first of these inequalities implies that for any $q>0$, we have

$$
v^{\prime}\left(g_{\alpha}^{B}\right)>\mu_{\alpha}^{B}-\frac{q}{1-q} \mu_{\beta}^{B}
$$

Step 2: Show that $c_{1}^{B}>c_{1}^{*}$ holds for all $q>0$. Suppose, to the contrary, that $c_{1}^{B} \leq c_{1}^{*}$ held for some $q>0$. Then (10) and (24) would imply

$$
(1-q) \mu_{\alpha}^{B} \geq(1-q) \mu_{\alpha}^{*}+q \mu_{\beta}^{*}
$$

In addition, $1-\theta c_{1}^{B} \geq 1-\theta c_{1}^{*}$ would imply $\mu_{\beta}^{B}<\mu_{\beta}^{*}$. Combining these two inequalities yields

$$
\mu_{\alpha}^{B}-\frac{q}{1-q} \mu_{\beta}^{B}>\mu_{\alpha}^{*}
$$

The inequality in (42) and condition (25) would then imply $v^{\prime}\left(g_{\alpha}^{B}\right)>v^{\prime}\left(g_{\alpha}^{*}\right)$ and, hence,

$$
g_{\alpha}^{B}<g_{\alpha}^{*}
$$

Note that (43) would also immediately imply $\mu_{\alpha}^{B}>\mu_{\alpha}^{*}$ which, using (5), would imply

$$
c_{2 \alpha}^{B}<c_{2 \alpha}^{*}
$$

However, combining the assumed relationship $c_{1}^{B} \leq c_{1}^{*}$ with (44) and (45), we would have

$$
\theta c_{1}^{B}+(1-\theta)\left(\frac{\widehat{\pi}_{\alpha}}{R^{\frac{1-\gamma}{\gamma}}}+1-\widehat{\pi}_{\alpha}\right) \frac{c_{2 \alpha}^{B}}{R}+g_{\alpha}^{B}<\theta c_{1}^{*}+(1-\theta)\left(\frac{\widehat{\pi}_{\alpha}}{R^{\frac{1-\gamma}{\gamma}}}+1-\widehat{\pi}_{\alpha}\right) \frac{c_{2 \alpha}^{*}}{R}+g_{\alpha}^{*} .
$$


In other words, all components of the resource constraint in state $\alpha$ would be smaller under the bailouts regime than under the Pigouvian regime, which contradicts the fact that the resource constraint holds with equality in both cases. Therefore, $c_{1}^{B}>c_{1}^{*}$ must hold.

Step 3: Show $\Phi^{B} \supset \Phi^{*}$. Consider any economy in $\Phi^{*}$, that is, any economy for which $c_{1}^{*} \geq c_{2 \beta}^{*}$ holds. The result from Step 2 tells us that $c_{1}^{B}>c_{2 \beta}^{*}$ also holds for this economy, which, together with (5) and (10), implies

$$
(1-q) \mu_{\alpha}^{B}<\frac{1}{R} \mu_{\beta}^{*}
$$

Furthermore, it follows from Step 2 that $1-\theta c_{1}^{B}<1-\theta c_{1}^{*}$ holds, which implies $\mu_{\beta}^{B}>\mu_{\beta}^{*}$. Therefore, we have

$$
(1-q) \mu_{\alpha}^{B}<\frac{1}{R} \mu_{\beta}^{B}
$$

which, using (5) and (10), implies $c_{1}^{B}>c_{2 \beta}^{B}$ and, hence, the economy is also in $\Phi^{B}$. Moreover, the fact that the inequality in (46) is strict implies that the inclusion relationship is also strict: there exist economies for which $c_{1}^{*}$ is slightly smaller than $c_{2 \beta}^{*}$, but (46) still holds. Alternatively, it is easy to find examples of economies that belong to $\Phi^{B}$ but not to $\Phi^{*}$; see Figure 5 .

Step 4: Show $\Phi^{N} \supset \Phi^{*}$. For any $e \in \Phi^{*}$, we know that $c_{1}^{*} \leq c_{2 \beta}^{*}$ holds. Using (5) and (24), this condition can be rewritten as

$$
\frac{\mu_{\alpha}^{*}}{\mu_{\beta}^{*}} \leq \frac{R^{-1}-q}{1-q}
$$

The second inequality in (39) then implies

$$
\frac{\mu_{\alpha}^{N}}{\mu_{\beta}^{N}}<\frac{R^{-1}-q}{1-q}
$$

Straightforward algebra, using (5) and (19), shows that this latter inequality is equivalent to $c_{1}^{N}>$ $c_{2 \beta}^{N}$, meaning that $e \in \Phi^{N}$ also holds. Once again, the fact that this inequality is strict implies that the inclusion relationship is also strict: there exist economies for which $c_{1}^{*}$ is slightly smaller than $c_{2 \beta}^{*}$, but $c_{1}^{N} \geq c_{2 \beta}^{N}$ still holds. Alternatively, it is easy to find examples of economies that belong to $\Phi^{N}$ but not to $\Phi^{*}$; see Figure 5. Together, the results in Steps 3 and 4 establish the proposition.

Proposition 10: For any $e \in \Phi^{*}$ with $q>0, W^{*}>\max \left\{W^{B}, W^{N}\right\}$.

Proof: I will show that the equilibrium allocation of resources under the Pigouvian regime attains the highest possible level of welfare conditional on investors following strategy profile (1). It then follows that the welfare levels associated with $\mathbf{c}^{B}$ and $\mathbf{c}^{N}$ are both strictly lower. 
Suppose a benevolent planner could control all endowments and operate both the intermediation technology and the public sector. This planner cannot control investors' withdrawal decisions and is subject to the same informational constraints as are intermediaries and the policy maker. In particular, the planner observes the state $s$ only after a fraction $\theta$ of investors have withdrawn. If investors follow the partial-run strategy profile in (1), what is the planner's best response?

Because investors are risk averse, the planner will choose to give the same amount of consumption, $\widehat{c}_{1}$, to each investor who withdraws before the state is revealed. Once she has observed the state to be $s$, the planner will choose to give common amounts $\left(\widehat{c}_{1 s}, \widehat{c}_{2 s}\right)$ to each of the remaining impatient and patient investors, respectively, and will provide an amount $g_{s}$ of the public good. In other words, the planner's best response to the strategy profile (1) can be summarized by a vector

$$
\mathbf{c} \equiv\left\{c_{1},\left\{c_{1 s}, c_{2 s}, g_{s}\right\}_{s=\alpha, \beta}\right\}
$$

in exactly the same way that the best responses of intermediaries and the policy maker can in the decentralized economy. The elements of this vector will be chosen to maximize

$$
\begin{array}{r}
\theta u\left(c_{1}\right)+(1-q)\left((1-\theta)\left[\widehat{\pi}_{\alpha} u\left(c_{1 \alpha}\right)+\left(1-\widehat{\pi}_{s}\right) u\left(c_{2 \alpha}\right)\right]+v\left(g_{\alpha}\right)\right)+ \\
q\left((1-\theta)\left[\widehat{\pi}_{\beta} u\left(c_{1 \beta}\right)+\left(1-\widehat{\pi}_{\beta}\right) u\left(c_{2 \beta}\right)\right]+v\left(g_{\beta}\right)\right)
\end{array}
$$

subject to the resource constraints

$$
\theta c_{1}+(1-\theta)\left(\widehat{\pi}_{s} c_{1 s}+\left(1-\widehat{\pi}_{s}\right) \frac{c_{2 s}}{R}\right)+g_{s} \leq 1
$$

for $s=\alpha, \beta$. Letting $\mu_{s}$ denote the multiplier on the resource constraint in state $s$, the first-order conditions characterizing the solution to this problem are

$$
\begin{aligned}
u^{\prime}\left(c_{1}\right) & =(1-q) \mu_{\alpha}+q \mu_{\beta} \quad \text { and } \\
u^{\prime}\left(c_{1 s}\right) & =R u^{\prime}\left(c_{2 s}\right)=v^{\prime}\left(g_{s}\right)=\mu_{s}
\end{aligned}
$$

for $s=\alpha, \beta$. It is straightforward to show that the equations characterizing the equilibrium allocation vector $\mathbf{c}^{*}$ under the Pigouvian regime, which are (4) - (6), (13) - (15), (24) and (25), can be reduced to precisely equations (47) - (49). This fact demonstrates that $\mathbf{c}^{*}$ solves the problem of the benevolent planner and, since this solution is unique, must generate strictly higher welfare than either $\mathbf{c}^{B}$ or $\mathbf{c}^{N}$. 


\section{References}

Allen, F. and Gale, D. (2004) “Financial fragility, liquidity, and asset prices” Journal of the European Economic Association, 2, 1015-1048.

Andolfatto, D., Nosal, E., and Wallace, N. (2007) "The role of independence in the Green-Lin Diamond-Dybvig model” Journal of Economic Theory, 137, 709-715.

Basel Committee on Banking Supervision (BCBS, 2013) "Basel III: The Liquidity Coverage Ratio and liquidity risk monitoring tools” Available at www.bis.org/publ/bcbs238.pdf

Bianchi, J. (2012), “Efficient bailouts?” NBER Working Paper No. 18587.

Boyd, J.H., Chang, C. and Smith, B.D. (2002) “Deposit insurance: A reconsideration” Journal of Monetary Economics, 49, 1235-1260.

Carlsson, H. and van Damme, E. (1993) "Global games and equilibrium selection” Econometrica, 61, 989-1018.

Chari, V.V. and Kehoe, P.J. (2009) “Bailouts, time inconsistency and optimal regulation” Federal Reserve Bank of Minneapolis Staff Report, November.

Cooper, R. and Kempf, H. (2011) "Deposit insurance without commitment: Wall Street versus Main Street” NBER Working Paper No. 16752.

Cooper, R. and Ross, T.W. (1998) "Bank runs: liquidity costs and investment distortions” Journal of Monetary Economics, 41, 27-38.

Diamond, D.W. and Dybvig, P.H. (1983) “Bank runs, deposit insurance, and liquidity” Journal of Political Economy, 91, 401-419.

Dijsselbloem, J. (2013) Speech given at the conference "Blueprint for a deep and genuine European Monetary Union” Brussels, July 5. Available at: http://www.government.nl/ government/membersof-cabinet/jeroen-dijsselbloem/speeches

Ennis, H.M. and Keister, T. (2009a) “Bank runs and institutions: The perils of intervention” American Economic Review, 99, 1588-1607.

Ennis, H.M. and Keister, T. (2009b) "Run equilibria in the Green-Lin model of financial intermediation” Journal of Economic Theory, 144, 1996-2020.

Ennis, H.M. and Keister, T. (2010) “Banking panics and policy responses” Journal of Monetary Economics, 57, 404-419.

Farhi, E. and Tirole, J. (2012) "Collective moral hazard, maturity mismatch and systemic bailouts" American Economic Review, 102, 60-93.

Freeman, S. (1988) “Banking as the provision of liquidity” Journal of Business 61: 45-64.

Gale, D. and Vives, X. (2002) “Dollarization, bailouts, and the stability of the banking system” Quarterly Journal of Economics, 117, 467-502. 
Goldstein, I. and Pauzner, A. (2005) "Demand deposit contracts and the probability of bank runs" Journal of Finance, 60, 1293-1327.

Green, E.J. (2010) “Bailouts” Federal Reserve Bank of Richmond Economic Quarterly, 96,11-32.

Green, E.J. and Lin, P. (2000) "Diamond and Dybvig's classic theory of financial intermediation: What's missing?” Minneapolis Fed Quarterly Review, 24 (Winter), 3-13.

Green, E.J. and Lin, P. (2003) "Implementing efficient allocations in a model of financial intermediation” Journal of Economic Theory, 109, 1-23.

Kocherlakota, N. (2010) "Taxing risk and the optimal regulation of financial institutions" Federal Reserve Bank of Minneapolis Economic Policy Paper 10-3.

Martin, A. (2006) "Liquidity provision vs. deposit insurance: preventing bank panics without moral hazard" Economic Theory, 28, 197-211.

Niepmann, F. and Schmidt-Eisenlohr, S. (2013) "Bank bailouts, international linkages and cooperation” American Economic Journal: Economic Policy, 5(4), 270-305.

Nosal, J. and Ordoñez, G. (2013) “Uncertainty as commitment” NBER Working Paper No. 18766.

Peck, J. and Shell, K. (2003) “Equilibrium bank runs” Journal of Political Economy, 111, 103-123.

Perotti, E. and Suarez, J. (2011) “A Pigouvian approach to liquidity regulation” International Journal of Central Banking, 7, 3-41.

Postlewaite, A. and Vives, X. (1987) “Bank runs as an equilibrium phenomenon” Journal of Political Economy, 95, 485-491.

Ranciere, R. and Tornell, A. (2011) "Financial liberalization: Efficiency Gains and Black Holes” mimeo., October.

Rehm, B. (2013) "Fed's Lacker: How to stop bailouts for good” American Banker, February 6. Available at: http://www.americanbanker.com/issues/178_26/fed-s-lacker-how-to-stop-bailoutsfor-good-1056577-1.html

Rochet, J.-C. and Vives, X. (2004) "Coordination failures and the lender of last resort: Was Bagehot right after all?” Journal of the European Economic Association, 2,1116-1147.

Stein, J.C. (2013) "Liquidity regulation and central banking” Speech to the 2013 Credit Markets Symposium sponsored by the Federal Reserve Bank of Richmond, Charlotte, North Carolina, April 19.

Swagel, P. (2010) “Yes, it’s a bailout bill” The American Magazine, April 24. Available at http://www.american.com/archive/2010/april/yes-its-a-bailout-bill

Wallace, N. (1988) "Another attempt to explain an illiquid banking system: the Diamond and Dybvig model with sequential service taken seriously” Minneapolis Fed Quarterly Review, 12 (Fall), 3-16.

Wallace, N. (1990) “A banking model in which partial suspension is best” Minneapolis Fed Quarterly Review, 14 (Fall), 11-23. 